\title{
MOVEMENT OF SELECTED NEARSHORE TEMPERATE REEF FISHES ALONG CALIFORNIA'S CENTRAL COAST
}

\author{
A Thesis Presented to the \\ Biological Sciences Faculty \\ California Polytechnic State University \\ In Partial Fulfillment \\ Of the Requirements for the Degree \\ Master of Science in Biological Sciences
}

by

Leslie Jaye Longabach

2010 
Copyright (C) 2010

Leslie Jaye Longabach

ALL RIGHTS RESERVED 


\section{COMMITTEE PAGE}

TITLE: Movement of Selected Nearshore Temperate Reef Fishes Along California's Central Coast

AUTHOR: Leslie Jaye Longabach

DATE SUBMITTED: September 2010

\section{Royden Nakamura, Ph.D.}

Committee Chair

\section{Dean E. Wendt, Ph.D.}

Committee Member

John S. Stephens Jr., Ph.D.

Committee Member 


\section{ABSTRACT \\ Movement of Selected Nearshore Temperate Reef Fishes Along California's Central Coast}

\section{Leslie Jaye Longabach}

Worldwide fisheries decline has spurred the utilization of new conservation and management approaches, including the implementation of marine reserves. The diversity of goals and expected outcomes should guide the marine reserve design process, coupled with a thorough understanding of the ecology of all species targeted for protection. Central California's network of coastal marine protected areas (MPAs) was established in an environment of some uncertainty regarding the expected outcomes for temperate nearshore fish species, especially the Sebastes genus (rockfishes). Movement behavior of temperate reef-fishes plays an important role in the level of protection that a reserve will afford a species. Consistent small-scale movements $(<10 \mathrm{~km})$ and limited home range sizes decrease the likelihood that individuals will encounter fishing mortality. Conversely, large-scale movements outside of reserve boundaries may contribute to fisheries in surrounding waters ('spillover').

The current study sought to further elucidate the movement behavior of some shallow-water temperate reef fish species throughout California's central coast, with goals of providing useful data for future MPA design processes. Tag-and-recapture methodology was utilized in order to observe fish movements, centered on a public participation program for acquiring information on recaptured tagged fishes. A total of 
476 fishes representing 14 species were recaptured from a sample of 37,111 tagged (1.3\%) over a five-year period spanning 2005-2009. The majority (75\%) of distances traveled were less than one kilometer, however some species made consistent far-ranging travels on the order of hundreds of kilometers as well. Analyses of factors with potential for shaping movement behavior included geographic variation, source of recapture data, gear type, days at liberty, length, initial capture depth, handling condition, and fish density. Additionally, the applicability of tag-and-recapture methodology is examined as an effective source of fish movement information. The results of this research corroborate findings of previous studies as well as provide new insight into the movement patterns of some nearshore temperate reef species. 


\section{ACKNOWLEDGEMENTS}

I would like to acknowledge the many people who contributed to my experience in completing this thesis project, as it is rooted in the collaborative efforts of a wide array

of individuals. I am forever grateful to my advisor, Dr. Royden Nakamura, for opening the doors of the Collaborative Fisheries team to me three years ago and granting me an opportunity to be a part of an inspiring and meaningful project. His wisdom and youthful love for life ensured that all learning pursuits were enjoyable. Dr. Dean Wendt has been a gift of a committee member in his tenacious pursuit of funding to support our projects as well as our personal survival as students. I will never forget his immense generosity both in financial support and in his insights into the ways of the world. It has been a privilege also to work with Dr. John Stephens, who has shared much of his rich history of research experiences while guiding me on my path. Many thanks to our collaborators at Moss Landing Marine Labs, especially Dr. Rick Starr and Noelle Yochum, who shared valuable data and patiently taught me the importance of diligence. Scot Lucas at California Department of Fish and Game also contributed to the data set by sharing his recapture information. Thanks to Nate Hall for daily support as a colleague and friend both in the Fish Lab and on the water. Larissa Ormonde was a tireless force of positivity and entertainment while conducting field work, and introduced me to the joys of GIS software. Our fisheries monitoring endeavors would not have been possible without help from the entire DEW lab, whose members contributed greatly in terms of logistics and camaraderie. Lastly, I would like to thank my parents, Kate and Jay Longabach, whose quiet support of my dreams allows me to feel blessed and fulfilled every day. 


\section{Table of Contents}

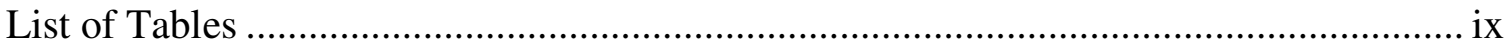

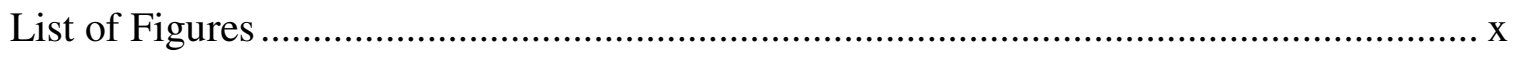

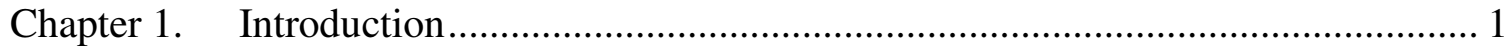

1.1 Collapse of Fisheries and MPAs as Conservation Tools ................................ 1

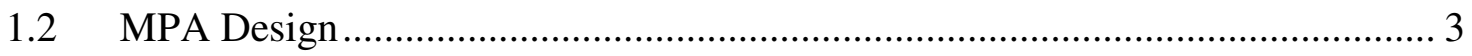

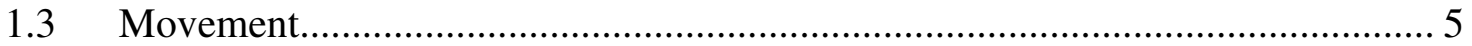

1.4 Movement Across MPA Boundaries .......................................................... 8

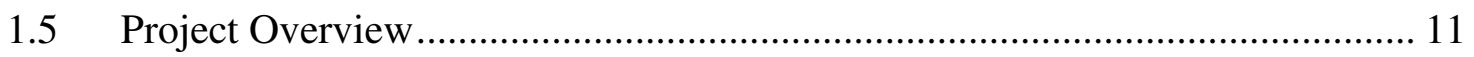

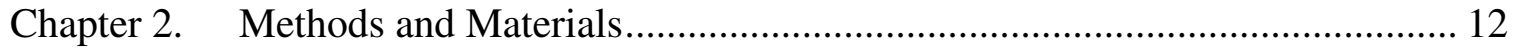

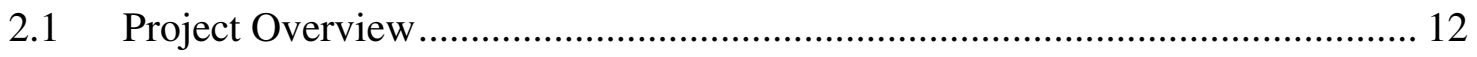

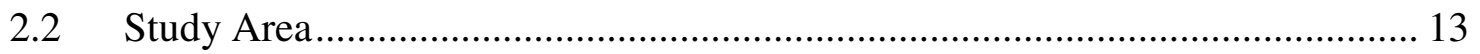

2.3 Hook-and-line Sampling Protocols ................................................................ 14

2.4 Commercial Trapping Sampling Protocols ................................................ 17

2.5 Public Awareness and Reward Program for Recaptured Fishes ....................... 18

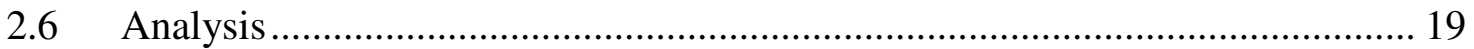

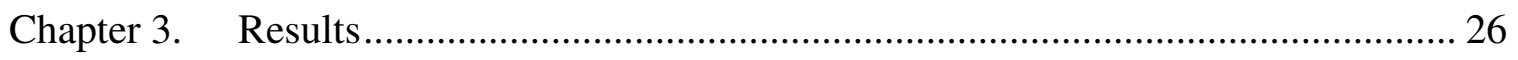

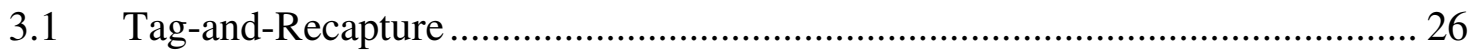

3.2 Geographic Variation in Fish Movements ................................................ 28

3.3 Source of Recapture Information ............................................................. 29

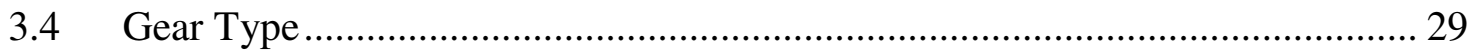

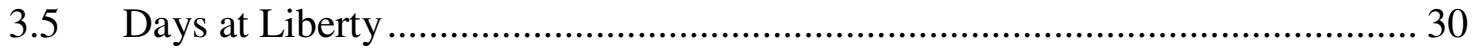

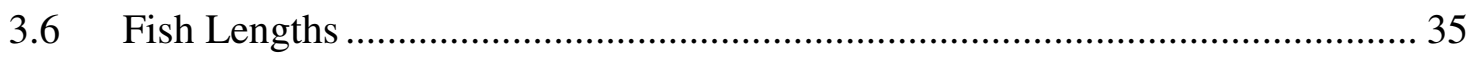

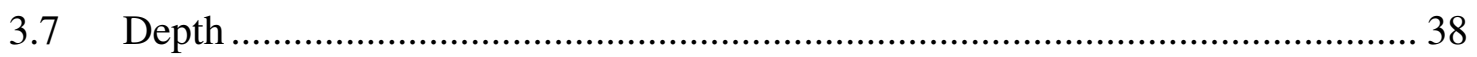

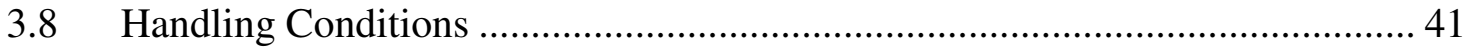

3.9 Catch-Per-Unit-Effort (CPUE) ............................................................... 42

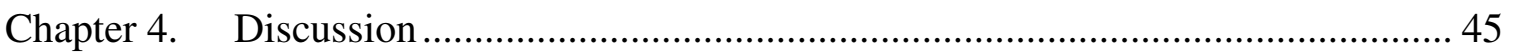

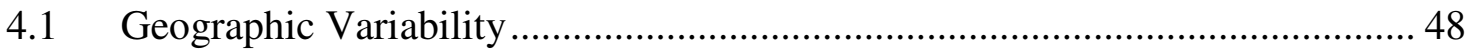

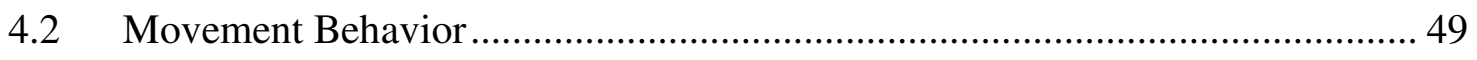

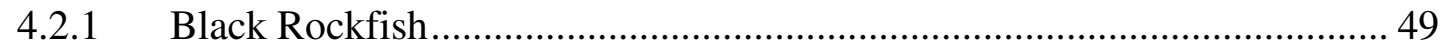




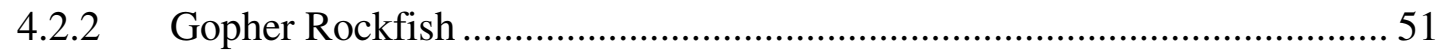

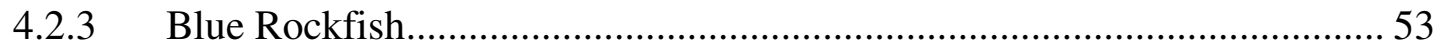

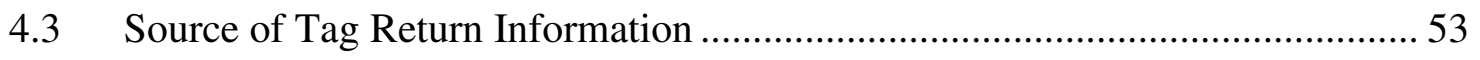

4.4 Central Coast MPA Design and Spillover................................................ 58

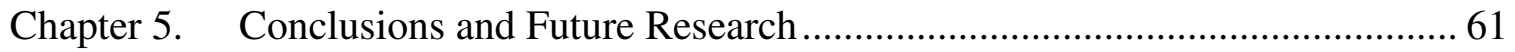

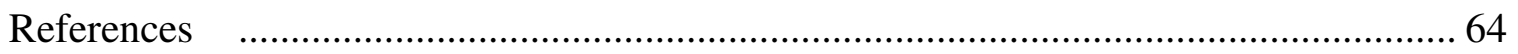




\section{List of Tables}

Table 1. Summary of recapture and movement information for all species reported as of $6 / 25 / 2010$.

Table 2. Summary of results for each factor analyzed among the three species with most recapture information, where ' $x$ ' represents a significant response in the data....... 48 


\section{List of Figures}

Figure 1. Map of the Central Coast and North Central Coast State Marine Conservation Areas (SMCA) and State Marine Reserves (SMRs) surveyed by the California Collaborative Fisheries Research Program hook-and-line project.

Figure 2. The State Marine Conservation Areas (SMCAs) and State Marine Reserves (SMRs) that were surveyed by the 2008 and 2009 California Collaborative Fisheries Research Program (CCFRP) trapping project.

Figure 3. The $500 \mathrm{~m} \times 500 \mathrm{~m}$ survey grid cells used for the hook-and-line project (a-d) and commercial trapping project (e-h). a) Año Nuevo SMCA, b) Point Lobos SMR, c) Piedras Blancas SMR, d) Point Buchon SMR, e) Año Nuevo SMCA (trapping), f) Point Lobos SMR (trapping), g) Piedras Blancas SMR (trapping), and h) Cambria SMCA (trapping).

Figure 4. Schematic of trap utilized in CCFRP commercial surveys....................... 24

Figure 5. Map of the central coast study region marine reserve network

Figure 6. Scatterplot of days at liberty vs. distance between capture events (m) for black rockfish recaptured by public fishers.

Figure 7. Scatterplot of days at liberty vs. distance between capture events $(\mathrm{m})$ for black rockfish recaptured during CCFRP surveys.

Figure 8. Scatterplot of days at liberty vs. distance between capture events $(\mathrm{m})$ for gopher rockfish recaptured by public fishers.

Figure 9. Scatterplot of days at liberty vs. distance between capture events $(\mathrm{m})$ for gopher rockfish recaptured during CCFRP surveys...

Figure 10. Scatterplot of days at liberty vs. distance between capture events $(\mathrm{m})$ for blue rockfish recaptured by public fishers and during CCFRP surveys.

Figure 11. Scatterplot of distance between capture events vs. original length for gopher rockfish.

Figure 12. Scatterplot of distance between capture events vs. original length for blue rockfish. 
Figure 13. Scatterplot of distance between capture events vs. original length for all black rockfish that traveled $<10 \mathrm{~km}$.

Figure 14. Scatterplot of distance between capture events vs. original length for all black rockfish that traveled $>10 \mathrm{~km}$.

Figure 15. Scatterplot of distance traveled vs. original capture depth for gopher rockfish.

Figure 16. Scatterplot of distance between capture events and original depth for blue rockfish.

Figure 17. Scatterplot of distance between capture events and original depth for black rockfish.

Figure 18. Scatterplot of distance traveled vs. original capture depth for black rockfish $<10 \mathrm{~km}$.

Figure 19. Distance vs. CPUE for gopher, blue, and black rockfishes captured during hook-and-line surveys that traveled $<10 \mathrm{~km}$ (CPUE units are fish-per-angler-hour)..... 43

Figure 20. Distance vs. CPUE for gopher, blue, and black rockfishes captured during hook-and-line surveys that traveled $>10 \mathrm{~km}$ (units are fish-per-angler-hour).

Figure 21. Distance vs. CPUE for all gopher, blue, and black rockfishes captured in traps (CPUE units are fish-per-trap-hour)...... 


\section{Chapter 1. Introduction}

\subsection{Collapse of Fisheries and MPAs as Conservation Tools}

Among the major threats to the world's oceans, fisheries overexploitation has played a central role in effecting structural and functional changes in coastal marine ecosystems over the centuries (Jackson et al. 2001). At present, almost $70 \%$ of fished stocks are listed as 'fully fished, overfished, depleted, or recovering' and are approaching, if not exceeding, world sustainable yield (World Resources Institute, 1996). The resultant biological effects include change in adult abundance, larval recruitment, juvenile growth rate and mortality, and total ecosystem production (Auster et al., 1996).

Coastal temperate reef-fish populations of the eastern Pacific share a plight with many other nearshore fisheries throughout the world. Population, biomass, and size composition have decreased for many species, including at least seven of the major commercial rockfishes (bocaccio, canary rockfish, cowcod, darkblotched rockfish, Pacific ocean perch, widow, and yelloweye rockfishes). Stock assessments for these species from 1999 to 2001 reveal that biomass is at or below $25 \%$ of the biomass estimated in the 1970s (Love et al., 2002). Changes in recreational catch also demonstrate fisheries decline as evidenced by the decrease in catch per unit effort (CPUE) aboard commercial passenger fishing vessels from 3,000 rockfish per 1,000 hours of fishing in 1980 to about 345 rockfish per 1,000 hours in 1996 (Love et al., 2002). As other rockfish grounds have declined, fishers, particularly in southern and central California, have begun exploiting a shallow-water (10m) live-rockfish fishery, presenting another source of fishing pressure. 
The widespread collapse in rockfish populations due to overfishing is compounded by the unique life history traits of the genus. The Sebastes genus is an exceptional group of the modern bony fishes in their uncommon mode of reproduction and relatively long life spans. In contrast to most fishes, the rockfishes engage in internal fertilization and give birth to live young. Individuals are capable of bearing larvae multiple times throughout their lifetime, and it has been noted that the longest-lived species could potentially give birth 100 times or more (Love et al., 2002). However, sustaining population size relies on recruitment (pelagic larvae surviving to become benthic juveniles), and many years may pass before the appropriate oceanographic patterns occur to ensure this. The highly overfished bocaccio rockfish provides an example of variable reproductive success in that the species experiences large numbers of recruitment only once every 20 years. The traits of slow-growth, unpredictable juvenile recruitment success, and late age-at-sexual-maturity all contribute to the rockfishes' exploitation vulnerability.

Traditional resource management practices, such as species and seasonal closures, quotas, and depth and gear restrictions have been utilized by resource managers for nearly a century in an attempt to conserve and rebuild fish stocks. However, due to the difficulty of enforcement and failure to meet goals, new conservation measures have emerged, including the establishment of harvest refugia, or marine protected areas (MPAs). The fundamental distinction between traditional fisheries management and the use of MPAs is the creation of geographical boundaries, and therefore, permanently protected space for target species within marine reserves (Davies, 1989; Rowley, 1994; Bohnsack, 1993). MPAs have the potential benefits of being relatively easy to manage, 
protecting and increasing fish stocks for spawning, and exporting larvae, recruits, and exploitable adults into adjacent fishing grounds (McClanahan \& Mangi, 2000). Additionally, marine reserves establish undisturbed populations and ecosystems with which to measure the effects of fishing as well as population parameters such as natural mortality, unexploited sex ratios, and within-species genetic diversity (Griffiths \& Wilke, 2002). There are currently over 1300 MPAs worldwide, and reserves are increasingly being proposed, evaluated, and implemented as conservation tools.

\subsection{MPA Design}

The design and implementation process for MPAs is complex due to both the diversity of conservation goals that must be considered and the unique needs posed by each goal. Management and preservation of collapsing fisheries comprise only a portion of the objectives mandated by the California Marine Life Protection Act of 1999, yet play dominant roles in shaping debate over the needs, benefits, and optimal design of MPAs (Gaines et al., 2003). Although the creation of California's system of coastal marine reserves has been the collaborative work of fisheries managers, scientific researchers, and stakeholders, the development of MPA proposal alternatives has occurred in an environment of limited understanding of ecosystem function (Walters et al. 2007). The ecological complexity in life histories and dispersal characteristics of marine organisms poses unique challenges in designing MPAs, and there is a strong need for accurate data to inform those involved in the process (Willis et al. 2003). 
Willis et al. (2003) note that the ability to use marine reserves as an effective fisheries management tool relies upon some simple behavioral and demographic assumptions regarding the fishery of interest. One such assumption is that in cases where the movement range of individuals is small in relation to the size of the reserve, those individuals will be spatially isolated from fishing mortality, and density within the reserve will be higher than in comparable fished areas. Another assumption is that elevated densities within the reserve will result in net emigration of biomass from the reserve to fished areas, either by random diffusion (Beverton \& Holt 1957) or densitydependent processes (Kramer \& Chapman 1999). Lastly, Willis et al. (2003) present the supposition that unfished populations of fishes are composed of relatively larger individuals. Since these individuals have greater fecundity, reserves will act as more productive sources of gametes than comparable fished areas.

Planning for the location, size, and spacing of a proposed marine reserve or network of reserves is interrelated with the ecology of a species of interest; however such planning has historically been addressed to a lesser extent in the design process (Kaplan \& Botsford, 2005). The geographical connectivity of marine reserves with regard to the exchange of individuals among sites has proven to be a crucial factor in meeting both conservation and management goals (Gaines et al. 2003). Oceanographic dynamics, such as advection, appear to play an influential role in determining the effectiveness of reserve configurations. The position of sites along a coastline accounts for differences in probabilities of larvae or adults arriving at particular locations (Kaplan \& Botsford 2005, Gaines et al. 2003). 
In considering proposed sizes of a marine reserve, Abesamis and Russ (2005) note that reserves established to benefit local fisheries must be large enough to promote population recovery, yet small enough to permit some emigration from the reserve . Ideally, optimal reserve size should be determined by the use of models incorporating information regarding the complex interactions of biological and environmental parameters relating to the many species within the region (Griffiths \& Wilke, 2002). Halpern \& Warner's (2002) comprehensive assessment of worldwide marine reserve performance over time $(n=80)$ found biological measures (population density, biomass, and average organism size) to be higher in marine reserves than in reference sites, regardless of reserve size. Their findings indicate that even small reserves can produce desired results, though likely at a slower rate than in large reserves due to greater organism dispersal from small reserves. To date, most no-take marine reserves are relatively small (median $4 \mathrm{~km}^{2}$ for $\mathrm{n}=70$ ), compared to the spatial scale of local populations of exploited marine organisms (Abesamis \& Russ 2005). The key to success may be in designing reserve size to accommodate the scales of movements of the particular organisms they aim to protect (Gell \& Roberts 2003).

\subsection{Movement}

Among the numerous fish species found on temperate reefs in central California, there exists a great diversity of life history strategies governing the movement behavior of individuals. Patterns have emerged allowing one to predict the degree of mobile or sedentary behavior based on depth, fish size, sex, age, reproductive timing, habitat 
availability and quality, oceanographic conditions, social interaction, and presence or absence of prey items (Starr et al. 2002; Hartmann 1987; Topping et al. 2006; Love 1980; Matthews 1990; Mireles 2005; Jagielo1990; Lowe et al. 2009). It is commonly believed that shallow-water ('intertidal', 'nearshore', and 'shallow shelf') species $(<70 \mathrm{~m})$ are more sedentary and undertake only small-scale movements, while deepwater ('deep shelf' and 'slope') species (>70 m) move about more extensively (Love, 1980). However, it has been reported that nearshore benthic rockfish densities decrease during the winter months and sometimes at night, suggesting that some degree of dispersal occurs (Matthews, 1986; Larson, 1980c). Meanwhile, inter- and intra-specific variation exists and past studies have produced inconsistent results regarding temperate reef-fish movements in the northeast Pacific Ocean.

The majority of fish movement research has focused on nearshore species (those found in the subtidal to $30 \mathrm{~m}$ depth) due to the greater ease of observation, tagging, and monitoring (Love et al., 2002). Movements of such species as lingcod and blue rockfish (Ophiodon elongates and Sebastes mystinus, respectively) have been investigated extensively, demonstrating a wide range of dispersal behaviors. Miller and Geibel (1973) found juvenile blue rockfish near Monterey, California, to move less from shallow kelp bed habitats $(60 \mathrm{~m})$ than from deeper reefs $(1.3 \mathrm{~km})$. This suggests that habitat quality has a substantial effect on dispersal. Likewise, lingcod showed varied movement behaviors in the same study, with the majority of tagged individuals remaining at the original capture site, and a small portion travelling up to $4.8 \mathrm{~km}$. Lingcod tagged with sonic transmitters in southeast Alaska demonstrated relatively small net movements within a marine reserve but made frequent round-trips of at least $2 \mathrm{~km}$ away from supposed 
territories. Additionally, $10 \%$ of the same lingcod population made longer forays, leaving an area for weeks or months, possibly in pursuit of prey or due to timing of spawning (Starr et al. 2004, Lowe et al. 2009). The movements of lingcod tagged in the Strait of Juan de Fuca near San Juan Island, Washington, varied greatly from nonmigratory to $50 \mathrm{~km}$ from the tagging site (Mathews \& La Riviere 1987).

Yellowtail rockfish (Sebastes flavidus) is a midwater species (90-180m) whose movements have been thoroughly investigated. It has been found to exhibit high site fidelity and homing abilities (Pearcy 1992) off Heceta Bank, Oregon yet exhibit extreme migratory behavior in movements up to $1400 \mathrm{~km}$ off southeast Alaska (Stanley et al. 1994). Such diversity in behavior is thought to be age-related, as evidenced by the movements of tagged adult yellowtail rockfish out of Puget Sound into open ocean waters, while the movements of juveniles in the same study were confined within the protected waters of the sound (Mathews \& Barker 1983).

Another mid-depth species, the black rockfish (Sebastes melanops), shows relatively sedentary behavior in addition to frequent far-ranging movements. In their Puget Sound mark-recapture study, Mathews and Barker (1983) found that over half of recovered black rockfish were recaptured at the original tagging site while the remainder had traveled 360-400 km away. Similarly, in a study conducted by the Washington Department of Fisheries, the majority of tagged black rockfish were recovered at the original capture location with the remainder being captured up to $40 \mathrm{~km}$ away (Mathews and Barker, 1983).

Tag and recapture studies, as well as ultrasonic telemetry, conducted with olive rockfish (Sebastes serranoides) show restricted movement between shallow reefs, yet 
substantial movement around deep-water oil platforms and other areas with presumably more cover (Love, 1980; Turner et al., 1969; Stein, 1997).

Although studies have been limited, deep-shelf and slope rockfish species (100200+ m) whose movement patterns have been explored demonstrate relatively longranging dispersal behavior, with some exceptions. Vermilion rockfish (Sebastes miniatus) have been observed to travel up to $15 \mathrm{~km}$ from their tagging site (Turner \& Ebert 1969) and two other deepwater species, bocaccio and chilipepper rockfishes (Sebastes paucispinis and Sebates goodie, respectively), have been found to travel over $10 \mathrm{~km}$ in southern California (Hartmann, 1987). Bocaccio and chilipepper rockfishes were also included in aggregations that moved over $2.4 \mathrm{~km}$ off a Santa Barbara Channel reef, possibly in pursuit of prey (Love, 1981). The majority of bocaccio tagged in a Monterey, California, study left a $12 \mathrm{~km}^{2}$ area, suggesting that both pelagic and "refugial" tendencies exist for the species (Love et al., 2002). Conversely, deepwater greenspotted rockfish (Sebastes chlorostictus), tend to leave submarine canyon-wall habitat on the order of only a few hundred meters though they may occasionally move up to $3 \mathrm{~km}$ away (Starr et al. 2002).

\subsection{Movement Across MPA Boundaries}

To be useful as fisheries management tools, no-take marine reserves must affect surrounding fished areas in a positive manner. Such effects should include the export of post-settlement adult and juvenile fish biomass across reserve boundaries, known as 'spillover' (Abesamis \& Russ 2005). However, the mechanisms and likelihood of such 
movement across reserve boundaries has been investigated only to a limited extent in existing MPAs. Fisheries yields adjacent to marine reserves are projected to be maintained or enhanced by spillover, with biomass export potentially compensating for the loss of fishing within the reserve (Zeller et al. 2003). However, protected areas may actually withdraw individuals from surrounding fisheries by attracting and retaining fish with higher habitat quality and food availability within the reserve. (Tremain et al. 2004). Emigration into marine reserves and bidirectional fish movement have been explored to an even lesser extent than spillover out of reserves (Amargos et al. 2010).

Biological mechanisms, such as density-dependent interactions may influence fish movements across reserve boundaries. Abesamis \& Russ (2005) observed a greater frequency (3.7 times) of aggressive interactions among adults within a Philippine marine reserve as compared with the area surrounding the reserve. The observed domination by larger fish in competitive interactions was proposed as a driver for home range relocation in smaller-sized individuals, and therefore, a potential mechanism for spillover. Amargos et al. (2010) experimentally demonstrated a spillover effect due to density dependence by extracting individual tropical reef fish from the unprotected side of a reserve boundary. Visual surveys had previously confirmed higher fish counts per unit area within the reserve, and by removing individuals on the unprotected side, the density gradient was further enhanced. The resultant observed net movement of fishes from the reserve to the nearby unprotected area provides an example of the projected response of adult fish to biomass build-up and space limitation inside MPAs.

Density-independent movement patterns will also determine the extent of protection that a reserve will afford a species and its contribution to adjacent fisheries. 
Ontogenetic shifts into new habitats, depth gradients, and reef zones occur among many fish species. On a smaller temporal and spatial scale, an individual's daily movements, or 'simple diffusion,' across reserve boundaries into fished areas will also affect levels of protection. If adults are highly migratory or have large territories, reserves will only offer protection for the percentage of the time individuals spend within the reserve boundaries (Kaplan \& Botsford, 2005).

It is also imperative to understand the likelihood of fish movements and spillover in the marine reserve design process, as immigration and emigration rates are often key parameters in building predictive models for reserve success. In a model created to investigate the likelihood that the California coastal MPA network would meet conservation objectives, Walters et al. (2007) found that modest dispersal rates of adult fish could substantially reduce abundance within protected areas when compared with predictions from models that ignored such dispersal. Models predict that marine reserves might not protect target species unless all degrees of movement are taken into account (Beaumariage, 1969; Rowley, 1994; Buxton \& Allen, 1989; Russ \& Alcala, 1996; Tremain, et al. 2004). The model of DeMartini (1993), developed for coral reef fishes, suggests that reserves are most likely to benefit fisheries relying on species with moderate vagility, because low-vagility fish do not move enough to significantly contribute to spillover, and high-vagility fish abundance is not greatly increased in reserves. 


\subsection{Project Overview}

This study is an examination of nearshore temperate reef fish movement based on a tag-and-recapture study along California's central coast. It is unique in that fishes were tagged both inside and outside of marine reserves beginning at the establishment of the protected area. The relationships governing movement patterns, including fish size, capture depth, days at liberty, latitude, and fish abundance are explored in order to elucidate behavioral trends. Additionally, tag-and-recapture methodology and its efficacy for tracking movement behavior are investigated. Among the 14 species recaptured, the largest amount of tag-return data was collected for black, gopher, and blue rockfishes; therefore, the analysis focuses on these three species. The scale of fish travel distances is subsequently compared to the current marine reserve network design to determine if sufficient protection and spillover of adults to adjacent fisheries are predictable. Based on previous studies of this nature, we expected to observe mostly small-scale movement by shallow-water, demersal species and farther-ranging movement by deeper-water, pelagic species. Our results confirmed these predictions as well as provided new insight into movement behavior not previously observed by some species. 


\section{Chapter 2. Methods and Materials}

\subsection{Project Overview}

Two distinct sets of sampling protocols were utilized by the California Collaborative Fisheries Research Program (CCFRP) in order to target central California nearshore fish species, including hook-and-line and commercial trap techniques. We conducted 118 hook-and- line fishing survey days between 2007 and 2009 and caught and tagged a total of 22,780 fishes, comprised of 40 species. In 2009, five experimental survey trips were additionally conducted in the proposed marine reserves at Duxbury Reef, the Farallon Islands, and Point Reyes. Forty-three trap surveys were completed during the fall and summer months of 2008 and 2009, during which period a total of 3,782 fishes were caught, representing 21 species. Identical sampling protocols were adopted by a California Department of Fish and Game (CDFG) research group out of Monterey, California and the data from their tag and recapture endeavor were utilized for the purposes of this investigation as well. They conducted both hook-and-line and trapping surveys from July through October of 2008 and 2009. A total of 1,604 fishes comprised of 18 species were tagged in the hook-and-line portion and 751 fishes comprised of 12 species were caught and tagged using trapping gear.

Additionally, data were utilized from the Groundfish Cooperative Research Project conducted by Dr. Rick Starr of Moss Landing Marine Labs. That study took place during the summer months of 2005 and 2006 and concentrated most fishing effort around Duxbury Reef off Bolinas, California. A total of 7,826 fishes from 21 species were caught and tagged during the project. All fishing was conducted using hook-andline gear and volunteer anglers, comparable to the hook-and-line portion of the CCFRP 
protocols. However, in this study fishing effort was not standardized, therefore precluding a catch-per-unit-effort estimate to be made with the data.

\subsection{Study Area}

The hook-and line surveys were conducted in four marine protected areas (MPAs) along the central California coast, including the Point Buchon, Piedras Blancas, and Point Lobos, State Marine Reserves (SMR) and Ano Nuevo State Marine Conservation Area (SMCA) (Figure 1) Sampling areas within the MPAs and corresponding reference sites were selected with input from the fishing, science, $\mathrm{NGO}$, and management communities with the objective of representing the nearshore rocky habitat that characterizes shallow waters off central California and are readily utilized by recreational and commercial fishers. The Point Buchon, Piedras Blancas, Point Lobos, Carmel Pinnacles and Ano Nuevo MPAs encompass areas of $6.7 \mathrm{mi}^{2}, 10.4 \mathrm{mi}^{2}, 5.4 \mathrm{mi}^{2}, 1 \mathrm{mi}^{2}$ and $10.2 \mathrm{mi}^{2}$ respectively. The commercial trapping surveys were conducted in the Cambria SMCA (2.3 $\mathrm{mi}^{2}$ ), Piedras Blancas SMR, Point Lobos SMR, and Ano Nuevo SMCA (Figure 2) and were similarly selected with input from the fishing, science, NGO, and management communities. Reference sites were chosen based on the criteria that they shared similar size, habitat, and oceanographic conditions with the nearby MPAs.

For both the hook-and-line and trapping surveys, $500 \mathrm{~m}$ x $500 \mathrm{~m}$ grid cells were created within each MPA and corresponding reference site, which were used to randomly select fishing locations each day of sampling (Figure 3). The grid cells were positioned in nearshore rocky habitats, in water less than 40 meters deep for the hook-and-line 
protocols and 20 meters deep for the trapping protocols in order to limit fishing mortality due to barotrauma. We utilized bathymetric maps as well as locations identified by fishers and boat captains as suitable habitat for nearshore fishes in selecting grid cell placement.

In 2008 and 2009 hook-and-line surveys were also conducted near Duxbury Reef off Bolinas, CA and in the proposed SMRs near Point Reyes, CA and the North and Southeast Farallon Islands. The same hook-and-line protocols were utilized in these locations as in the other MPAs except that sampling was not completed within $500 \mathrm{~m} \mathrm{x}$ $500 \mathrm{~m}$ grid cells.

\subsection{Hook-and-line Sampling Protocols}

Four hook-and-line survey days per month were conducted within each MPA and reference site pair throughout three mid-late summer months from 2007-2009 (Piedras Blancas SMR was surveyed 2008-09). We chartered commercial passenger fishing vessels (CPFVs) from local sportfishing companies and communicated our project protocols with the captain and crew of each boat prior to conducting surveys. Before each sampling day, four grid cells were selected at random and the corner coordinates

were provided to the CPFV captain with whom we were working that day. The captains' responsibilities included locating three discrete suitable fishing locations within the grid cell and completing a fifteen minute fishing drift in each. The same pattern of three fifteen-minute drifts was completed for all four grid cells. 
Hook-and-line fishing was conducted by volunteer anglers who we recruited through newspaper media coverage, various fishing clubs, online fishing websites, and from previous collaborative studies. Our requirements for the volunteer anglers were that they have experience with rockfish fishing, be over the age of 16 , and be capable of fishing consistently for six hours.

At the beginning of each survey day all volunteer anglers were assigned to a fishing station which corresponded to one of three types of terminal tackle. A third of the anglers fished using 'lingcod bars,' iron bars of various weights and shapes, with hooks attached and designed to appear as fishes' prey items. Another third of the anglers used two red or white mylar 'shrimp fly' lures with frozen squid strips on the hooks. The remaining third of anglers fished with two shrimp fly lures but without the frozen squid strips. Anglers used sinkers of 4-16 oz depending on the currents and all hooks were barbless. The number of anglers that fished at a given time was always divisible by three so that each gear type was fished with equal effort, and varied between three and twelve anglers throughout the sampling period.

Once the captain decided upon the fishing location he or she signaled the start of the drift and the anglers commenced fishing. If an angler experienced a problem with their fishing gear, such as being hooked on bottom substrate or having a tangled line, the 'science crew' or deckhand immediately provided them a new rod so they were fishing during the entire drift. However, if the time spent with fishing gear out of the water was one minute or more, it was noted on the data sheet and subtracted from the overall fishing effort. 
During each drift, the number of anglers fishing, and the start and end depths, time, and coordinates were recorded on data sheets. Surface water temperature was measured at each fishing location using the vessels' sensors, and bottom temperatures were recorded once per grid cell using a CTD. Water clarity was measured with a secchi disk once per grid cell as well. Cloud cover, bottom relief, number of fish-molesting pinnipeds, wind speed and direction, and swell height and direction were also noted on the data sheets during each drift.

Once a fish was caught, it was promptly and gently removed from the hook by the science crew, always with gloved hands so as not to introduce bacteria to the fish or damage its slime coating. Each fish was identified to species and measured in $\mathrm{cm}$ (total length) on a wooden v-board (Ano Nuevo and Point Lobos) or a flat plastic board (Piedras Blancas and Point Buchon). If a fish was at least $21 \mathrm{~cm}$ in length and in good condition, it was tagged with an external T-bar anchor tag (Floy Tag, model FD-.94), injected into the dorsal musculature between the second and third dorsal spines on the left side of the body. Printed on each tag were the institution name ('Cal Poly Bio Sci' or 'MLML'), phone number, and the instruction, “get lat/lon," as well as a unique identifying number. Tagged fishes were released as close to the capture location as possible.

In order to reduce incidental mortality, the time each fish spent on board the vessel was minimized and the effects of barotrauma were ameliorated with the use of hypodermic venting needles and a fish-descending device (an inverted and weighted plastic crate or the Ace Calloway Barotrauma-Reversing Fish Release). A coded number 
system was used to describe the condition of the fish upon release based on the external evidence of barotrauma and damage due to hooking or to predation.

\subsection{Commercial Trapping Sampling Protocols}

We conducted four survey days per month within each MPA/reference site pair during three late-summer months of 2008 and two months of 2009. The Ano Nuevo MPA was sampled during the 2008 season only. Fishing surveys were completed in collaboration with six local commercial trap fishermen, utilizing a trap design created specifically for our study in order to ensure standardization across all study sites (Fig. 4).

Before each sampling day, three grid cells, on average, were randomly selected and corner coordinates were provided to the captain. Within each grid cell, a total of twenty traps were deployed over suitable fishing habitat at the discretion of the captain. The twenty traps were divided into two groups of ten, with the first ten traps set in a discrete area of the grid cell from the second ten. Each trap was baited with a pint of frozen squid inside its bait box and left in the water for approximately one hour. For each trap deployed, the latitude, longitude, depth and time of deployment were recorded on data sheets. Swell height and direction, wind speed and direction, surface water temperature, and amount of cloud cover were also recorded for each grid cell.

Once the hour-long soak time had elapsed, traps were retrieved in the order of deployment and caught fishes were removed and processed. Fishes were identified and measured in $\mathrm{cm}$ (total length) using a wooden v-board (Ano Nuevo and Point Lobos) or a flat plastic measuring board (Piedras Blancas and Cambria). All fishes over $20 \mathrm{~cm}$ and in 
good condition were tagged in the dorsal musculature with an external T-bar anchor tag on the left side of the body. If a fish exhibited signs of barotrauma, its swimbladder was vented with a hypodermic needle and/or was released using a fish-descending device. The condition of each fish upon release was recorded based on a numbered system similar to that used in the hook-and-line project. Additionally, the common name and quantity of invertebrates captured was recorded for each trap.

\subsection{Public Awareness and Reward Program for Recaptured Fishes}

We began advertising for information on recaptured fishes at the onset of our sampling in the summer of 2007. Tag-return posters describing the study and how to report the capture of a tagged fish were posted throughout the central coast at key fishing locations and tackle shops. Information was also posted on our project's website and on those of local fishing forums and clubs. Commercial and recreational anglers notified us by telephone when they recaptured a tagged fish, at which time we collected information about the date, coordinates, depth of capture, species, length, and tag number. We offered a reward of twenty dollars for tag information, including incomplete reporting of the desired data. Additionally, we looked for previously tagged fishes in our sampling areas as we continued with the study. When we caught such a fish, we recorded its tag number, length, and coordinates, and released the fish again. 


\subsection{Analysis}

I utilized Arc Map Global Information Systems (GIS) computer software, in assessing fish movement data in this study. Statistical analyses were conducted using appropriate tests found in Minitab Version 16 software. Non-parametric data were transformed (log base 10) as appropriate to certain analyses. 


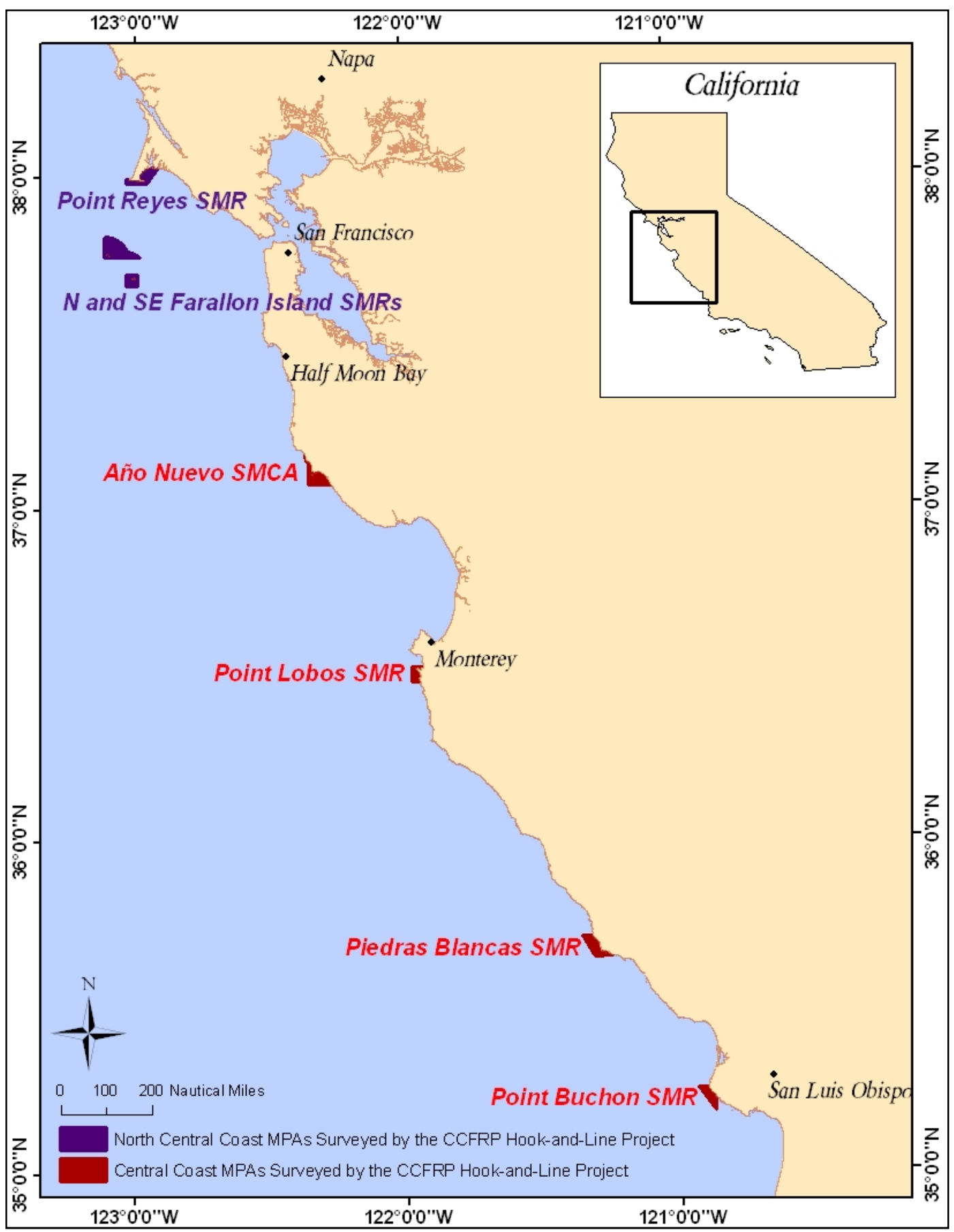

Figure 1. Map of the Central Coast and North Central Coast State Marine Conservation Areas (SMCA) and State Marine Reserves (SMRs) surveyed by the California Collaborative Fisheries Research Program hook-and-line project. 


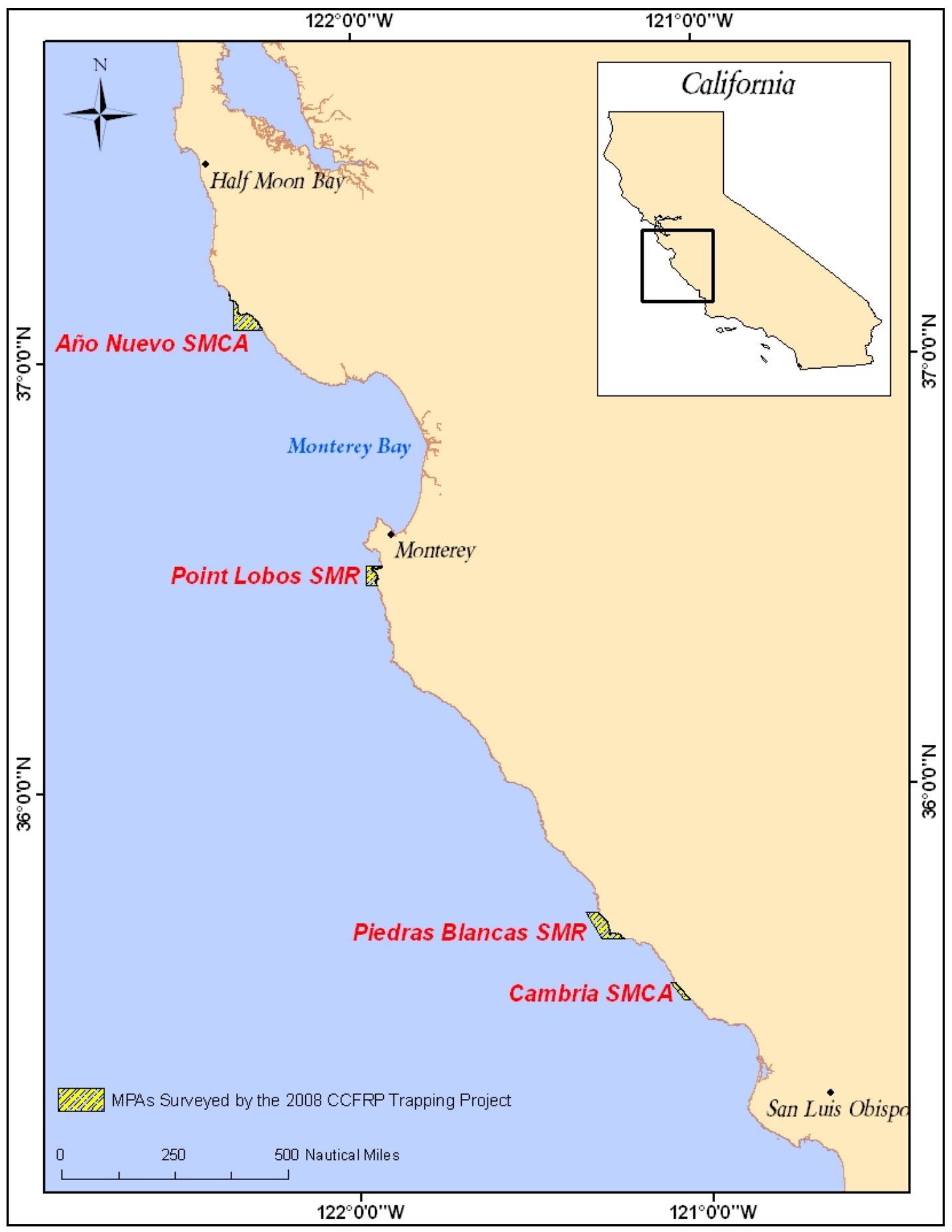

Figure 2. The State Marine Conservation Areas (SMCAs) and State Marine Reserves (SMRs) that were surveyed by the 2008 and 2009 California Collaborative Fisheries Research Program (CCFRP) trapping project. 
a)

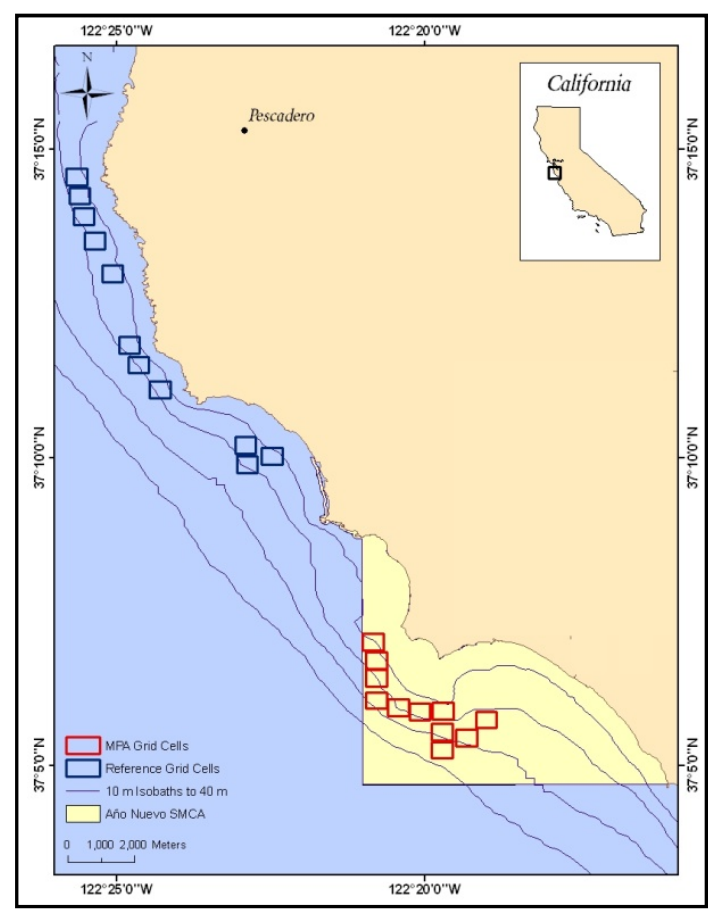

c)

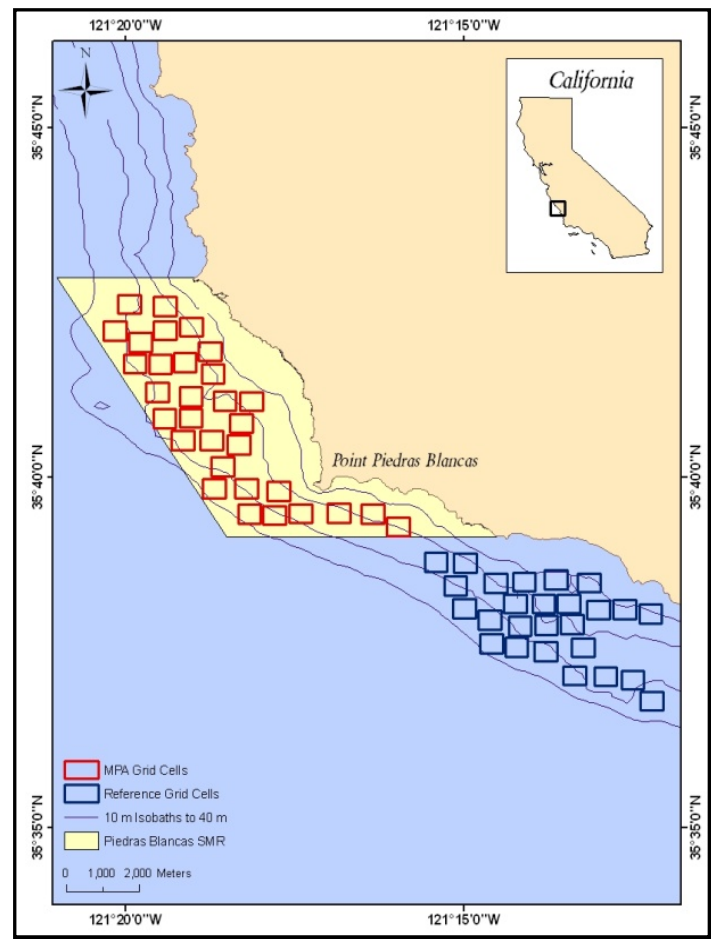

b)

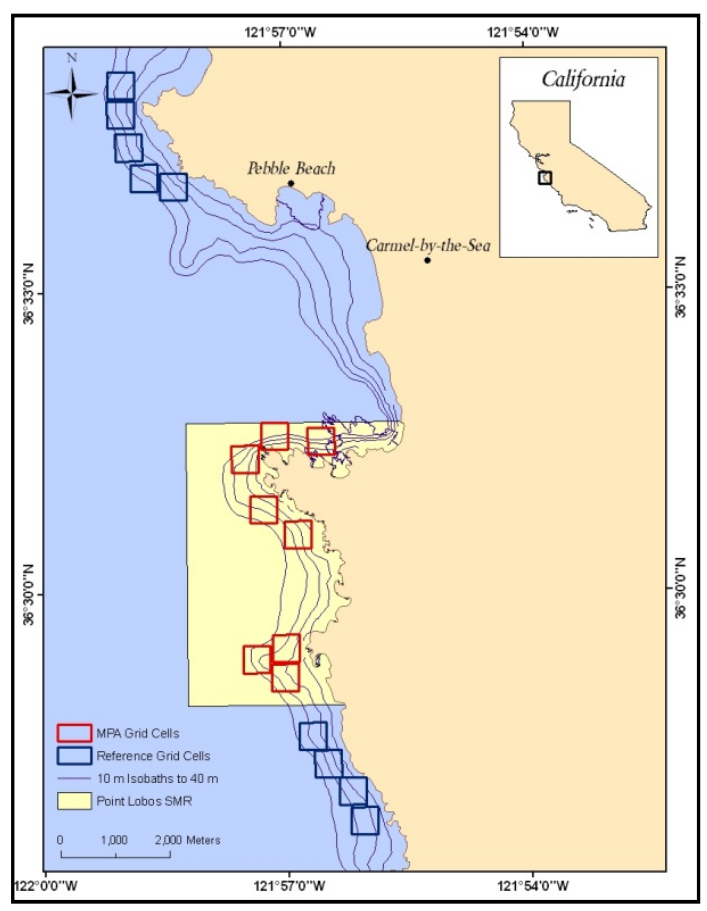

d)

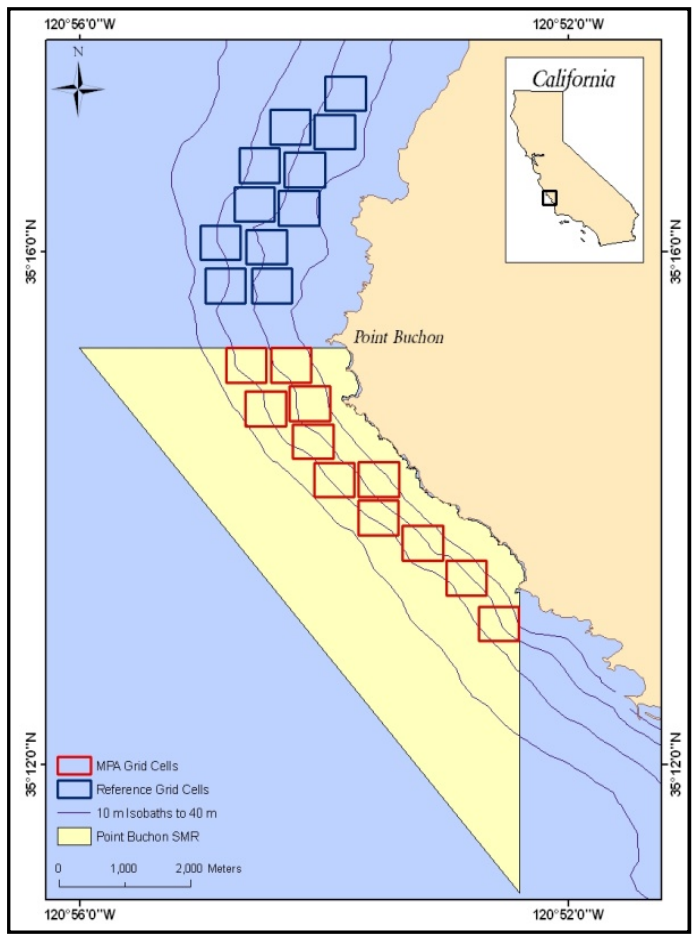


e)

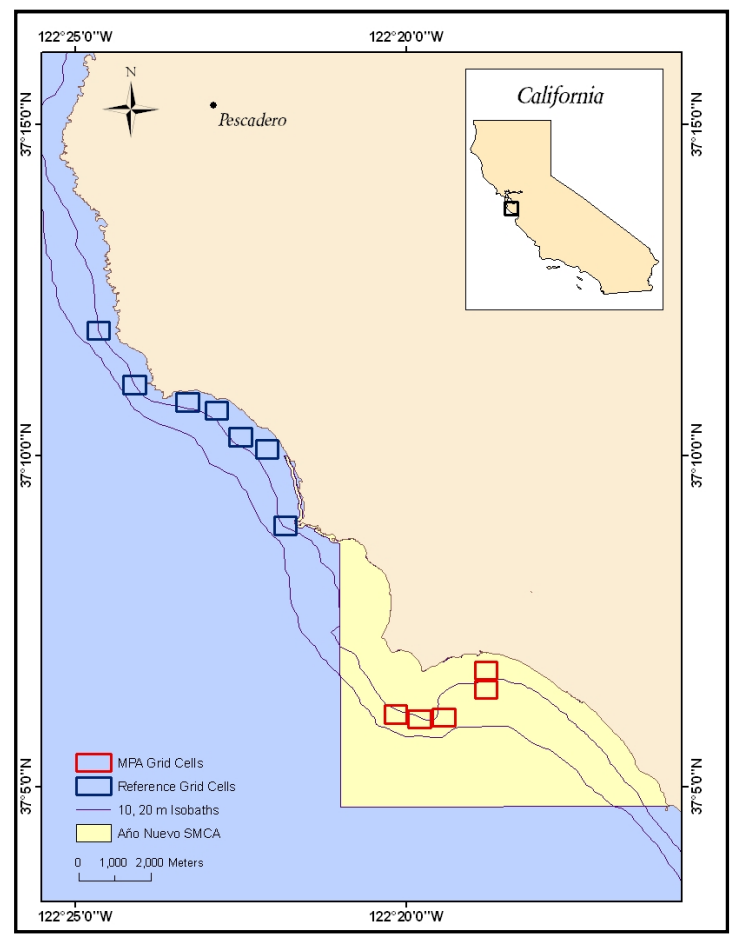

g)

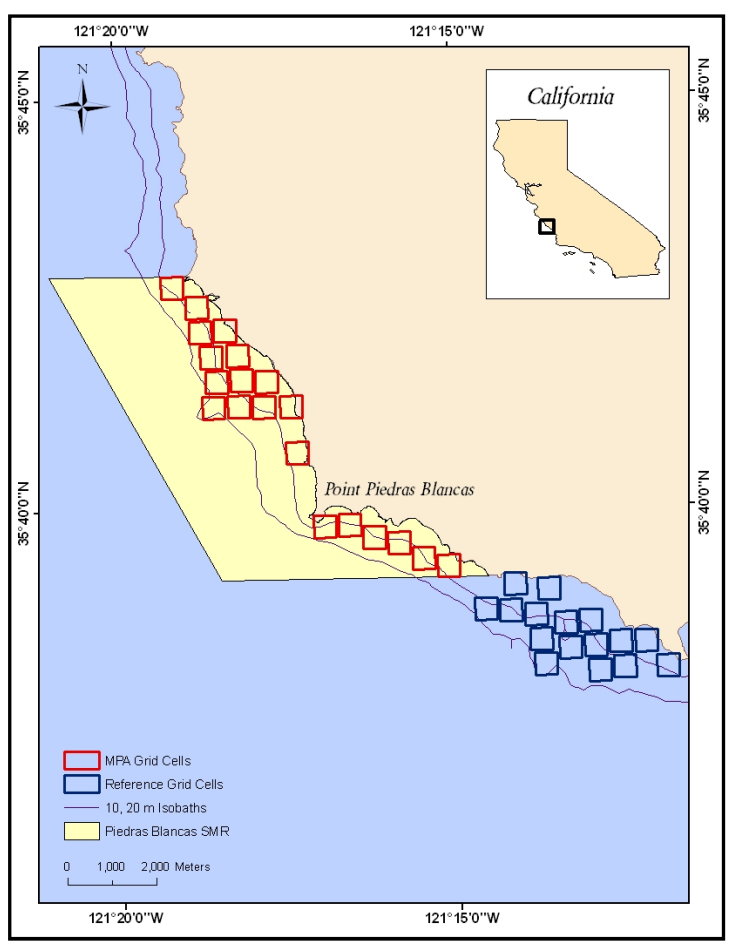

f)

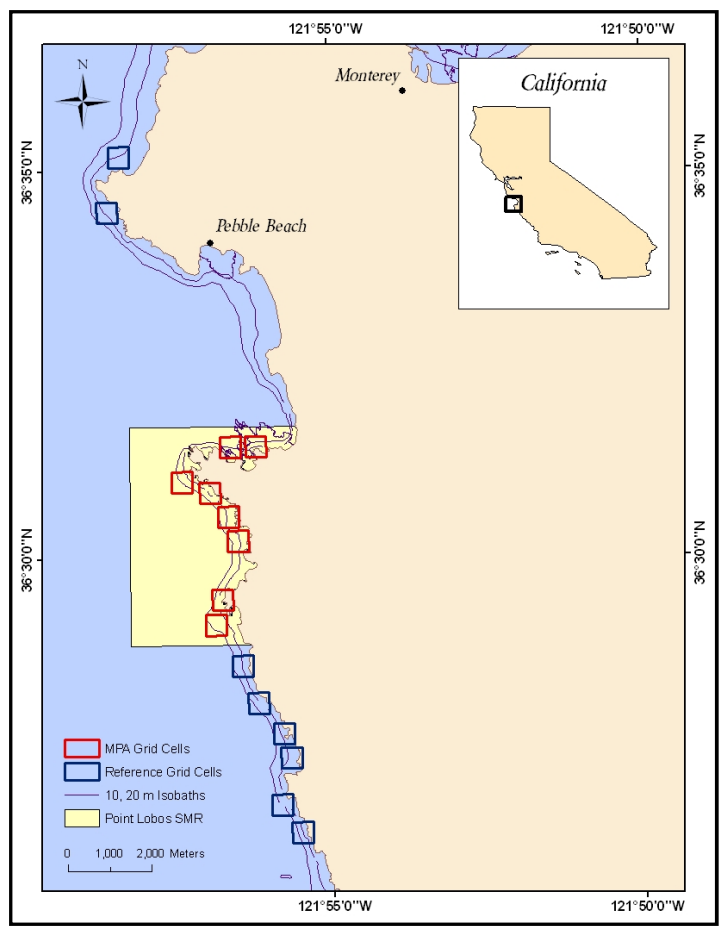

h)

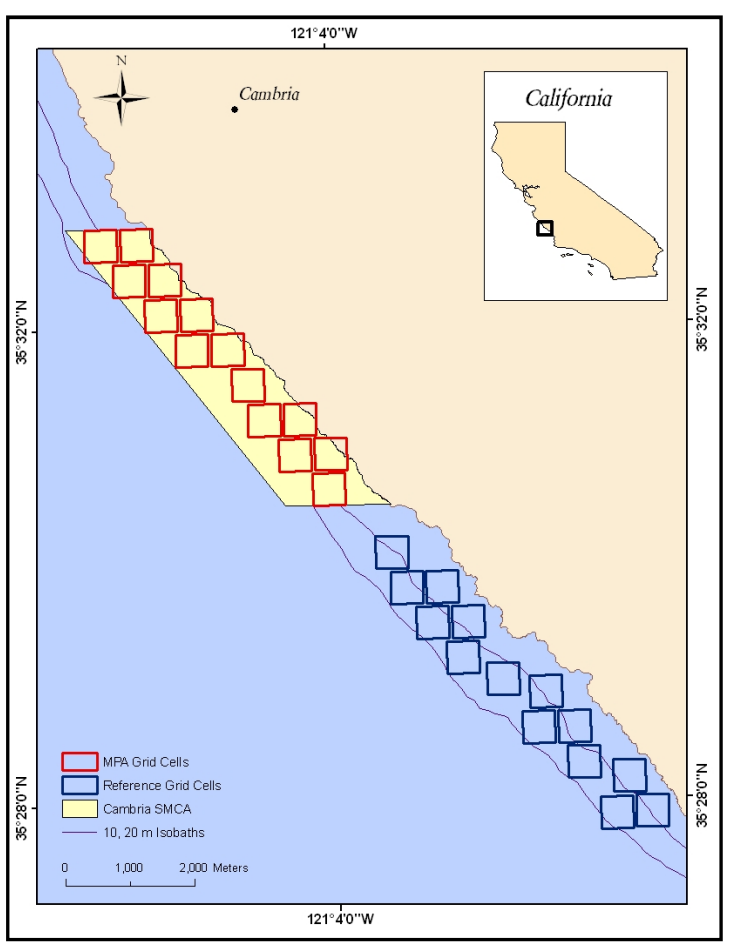

Figure 3. The $500 \mathrm{~m}$ x $500 \mathrm{~m}$ survey grid cells used for the hook-and-line project (ad) and commercial trapping project (e-h). a) Año Nuevo SMCA, b) Point Lobos 
SMR, c) Piedras Blancas SMR, d) Point Buchon SMR, e) Año Nuevo SMCA (trapping), f) Point Lobos SMR (trapping), g) Piedras Blancas SMR (trapping), and h) Cambria SMCA (trapping).

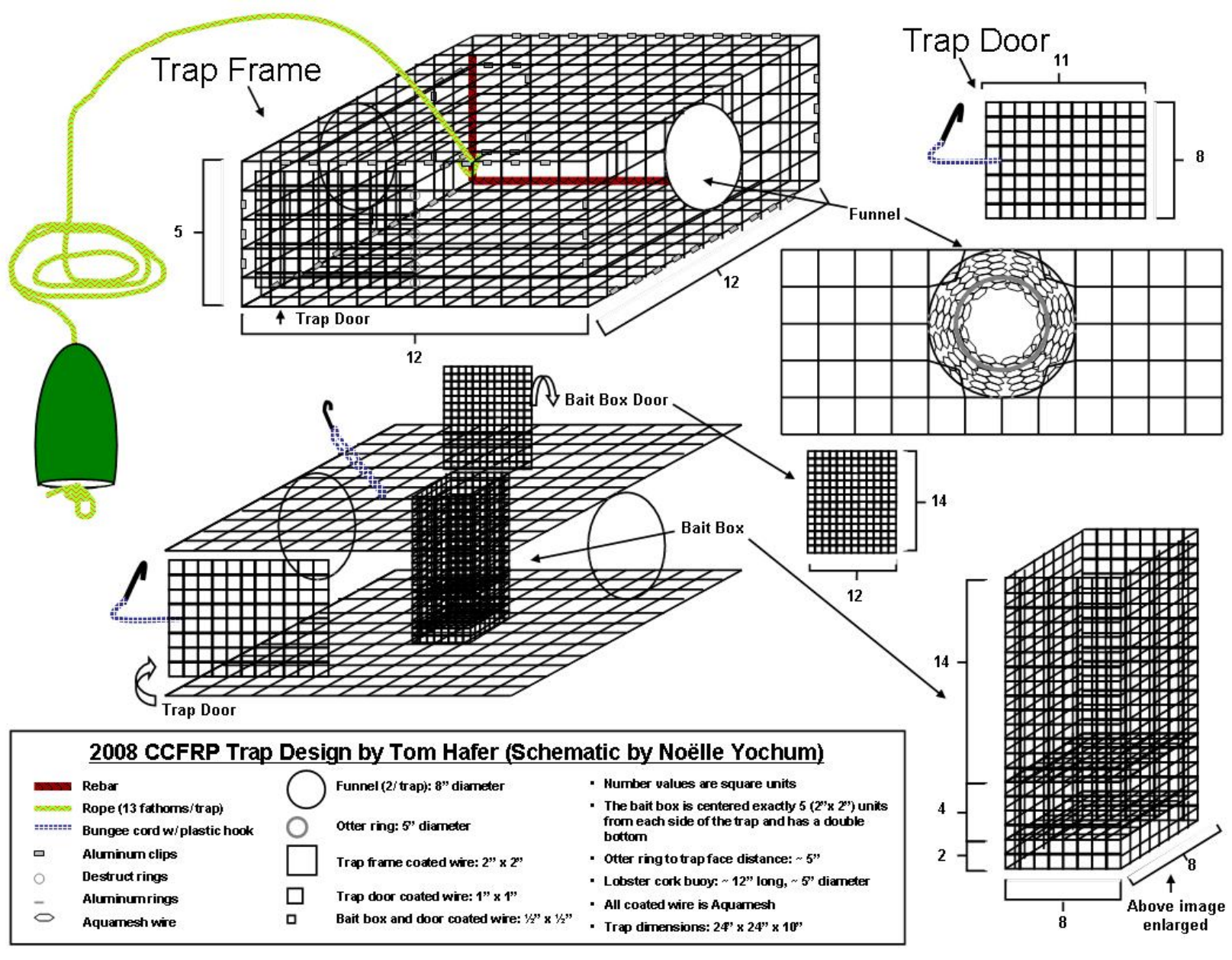

Figure 4. Schematic of trap utilized in CCFRP commercial surveys. 


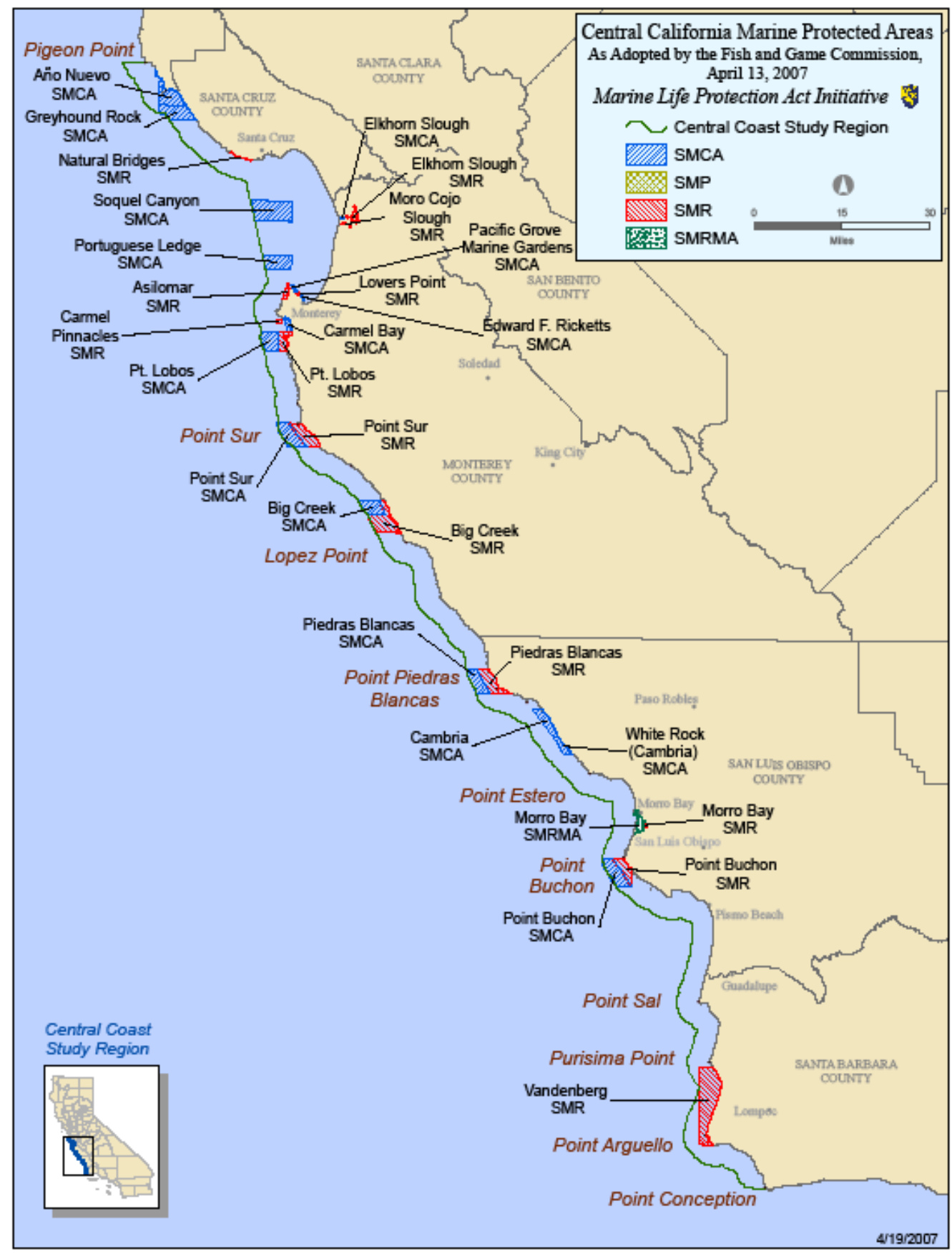

SMCA = state marine conservation area $\quad$ SMP = state marine park

SMR = state marine reserve $\quad$ SMRMA = state marine recreational management area

Figure 5. Map of the central coast study region marine reserve network. 


\section{Chapter 3. Results}

\subsection{Tag-and-Recapture}

A total of 476 fishes representing 14 species were recaptured from a sample of 37,111 tagged (1.3\%) over a five-year period spanning 2005-2009. Eleven of the 14 species are various rockfishes of the Sebastes genus. The remaining three are other nearshore temperate reef species, including lingcod (Ophiodon elongatus), cabezon (Scorpaenichthys marmoratus), and kelp greenling (Hexagrammos decagrammus). A summary of the descriptive statistics on all species tagged and recaptured during hookand-line and trap surveys throughout the CCFRP and the Duxbury Reef Groundfish Cooperative Research Project are provided in Table 1. These data are comprised of fishes originally tagged in the marine reserves and corresponding reference sites throughout the Central Coast study area, including Point Buchon, Piedras Blancas, Cambria, Point Lobos, Carmel Pinnacles, Ano Nuevo, Duxbury Reef, and the Farallon Islands. 
Table 1. Summary of recapture and movement information for all species reported as of $6 / 25 / 2010$

\begin{tabular}{|c|c|c|c|c|c|c|c|}
\hline $\begin{array}{c}\text { Species } \\
\text { (common } \\
\text { name) }\end{array}$ & $\begin{array}{l}\text { No. } \\
\text { tagged }\end{array}$ & $\begin{array}{c}\text { No. } \\
\text { Recaptured }\end{array}$ & $\underset{\%}{\text { Recapture }}$ & $\begin{array}{c}\text { Mean } \\
\text { distance } \\
(\mathbf{m})\end{array}$ & $\begin{array}{l}\text { SE of } \\
\text { mean }\end{array}$ & $\begin{array}{l}\text { Mean } \\
\text { days at } \\
\text { liberty }\end{array}$ & $\begin{array}{l}\text { SE of } \\
\text { mean }\end{array}$ \\
\hline Gopher RF & 9,552 & 118 & $1.2 \%$ & 1,090 & 463 & 312 & 19 \\
\hline Black RF & 7,307 & 222 & $3.0 \%$ & 26,782 & 8,287 & 215 & 16 \\
\hline Blue RF & 7,045 & 30 & $0.4 \%$ & 1,059 & 361 & 120 & 28 \\
\hline Cabezon & 692 & 16 & $2.3 \%$ & 1,101 & 902 & 183 & 39 \\
\hline Copper RF & 377 & 11 & $2.9 \%$ & 78 & 28 & 282 & 118 \\
\hline Olive RF & 1,976 & 7 & $0.4 \%$ & 843 & 801 & 152 & 55 \\
\hline Lingcod & 1,142 & 18 & $1.6 \%$ & 592 & 311 & 79 & 22 \\
\hline Kelp & 565 & 6 & $1.1 \%$ & 150 & 36 & 219 & 63 \\
\hline \multicolumn{8}{|l|}{ Greenling } \\
\hline Canary RF & 1,065 & 11 & $1.0 \%$ & 1,227 & 831 & 214 & 57 \\
\hline Brown RF & 989 & 22 & $2.2 \%$ & 1,262 & 407 & 262 & 57 \\
\hline Black \& & 744 & 3 & $0.4 \%$ & 116 & 111 & 282 & 69 \\
\hline \multicolumn{8}{|l|}{ Yellow } \\
\hline $\begin{array}{l}\text { Yellowtail } \\
\text { RF }\end{array}$ & 1,112 & 4 & $0.4 \%$ & 7,920 & 7,851 & 255 & 222 \\
\hline China RF & 301 & 2 & $0.7 \%$ & $\mathrm{n} / \mathrm{a}$ & $\mathrm{n} / \mathrm{a}$ & $\mathrm{n} / \mathrm{a}$ & $\mathrm{n} / \mathrm{a}$ \\
\hline Vermilion & 904 & 6 & $0.7 \%$ & 15,159 & 14,142 & 210 & 77 \\
\hline $\mathbf{R F}$ & & & & & & & \\
\hline
\end{tabular}

The mean distance traveled between tagging and recapture locations by all species combined was $11.1 \mathrm{~km} \pm 3.9 \mathrm{SE}$, however, over $75 \%$ of tagged fishes were recaptured less than $1 \mathrm{~km}$ from the tagging site. The range of distances traveled spans from zero to over $887 \mathrm{~km}$, with a median of $192 \mathrm{~m}$. Tagged fishes were at liberty between capture events, on average, $207 \pm 10.5 \mathrm{SE}$ days, ranging from zero to 1,518 days. The median number of days at liberty is 83 and $75 \%$ of fishes were recaptured within 350 days of being tagged. 
Due to the wide range of sample sizes available for each species as well as their greatly varied life history traits, each species' movements are considered separately throughout the remainder of this analysis.

\subsection{Geographic Variation in Fish Movements}

Individual species' movements between tag and recapture locations were examined among three zones of the central coast study region, designated as 'north', 'central' and 'south'. Fishes pertaining to the northern zone of the central coast are those originally captured and tagged near Duxbury Reef and the Farallon Islands, while fishes caught at Ano Nuevo, Carmel Pinnacles, and Point Lobos are considered part of the central portion of the central coast study region. Finally, fishes caught and tagged near Piedras Blancas, Cambria, and Point Buchon are pooled into the 'southern' central coast designation. A one-way ANOVA was used to test for differences in distances traveled among fishes of the three central coast regions for each species. Variances were tested using Levene's test for variance homogeneity and when appropriate data were logarithmtransformed to meet the test's assumptions. A Kruskal-Wallis non-parametric test was applied when ANOVA normality or variance assumptions could not be met.

Of the 14 species recaptured throughout the duration of this study, nine species have substantial sample sizes with location information to conduct a comparison of the geographic zones throughout the central coast. The species compared include black, blue, brown, canary, vermilion, yellowtail, and gopher rockfishes as well as cabezon and lingcod. None of the species examined show a significant difference in distance traveled 
between capture events throughout the north, central, or south regions of the central coast area. For this reason, movements of recaptured fishes are not separated further on a geographic basis but are considered as a collective pool of data, partitioned by individual species.

\subsection{Source of Recapture Information}

Travel distances were compared for each species with sufficient location data to determine if there is a significant difference in movement between tagged fishes recaptured by CCFRP (and Duxbury Reef Groundfish Cooperative Research Project) fishing surveys and those recaptured by public fishers, whether commercial or recreational. Of the nine species recaptured by both CCFRP surveys and public fishers, two species appear to demonstrate a detectable difference in movement distances when recaptured by either capture regime. Gopher and black rockfishes, both with the highest number of tag returns, were found to travel significantly greater distances between capture events when encountered by public fishers than by CCFRP hook-and-line or trapping surveys (Kruskal-Wallis $\mathrm{p}=0.000$ for both species).

\subsection{Gear Type}

Gopher rockfish was the only species to be originally captured by both hook-andline and trap gear types during CCFRP surveys and recaptured again by CCFRP and public fishers. Upon comparing the distances moved (natural log transformed) by fish 
originally captured by hook-and-line versus those caught in traps, it appears that those landed by hook-and-line traveled significantly greater distances than trapped fish (oneway ANOVA, $\mathrm{df}=1, \mathrm{n}=86, \mathrm{p}=0.002$ ). However, when distances traveled are further partitioned by recapture gear types (hook-and-line and trap) and between public fishers or CCFRP surveys, there does not appear to be a significant difference. That is, when gopher rockfish are originally tagged and recaptured by hook-and-line either by public fishers or CCFRP surveys, there is not a significant difference in distances traveled (oneway ANOVA, $\mathrm{df}=1, \mathrm{n}=40, \mathrm{p}=0.621$ ). This data, however, omits the farthest-traveling recaptured gopher rockfish, which traveled over $33 \mathrm{~km}$. The fish was originally caught on a CCFRP hook-and-line survey and was recaptured by a public commercial trap fisher, and thus did not conform to the comparison. Similarly, there is not a significant difference in fish movement when gopher rockfish are originally tagged and recaptured in traps by either public fishers or CCFRP surveys (one-way ANOVA, $\mathrm{df}=1, \mathrm{n}=35, \mathrm{p}=$ $0.104)$.

Based on the insignificant results of partitioning gopher rockfish movements by original and recapture gear type as well as by the source of the recapture information (public fisher or CCFRP survey), I will proceed in the analysis of the species' movements utilizing the source of the information as the more consequential factor.

\subsection{Days at Liberty}

The number of days between tagging and recapture events (days at liberty) was explored for the three species with the highest number of tag returns (black, gopher, \& 
blue rockfishes) in order to determine whether movement was randomly diffuse or directed. For black and gopher rockfishes' movement, data is separated by the source of the movement information (public fisher or CCFRP survey) as per the significant results of the Kruskal-Wallis test performed above.

There is a significant relationship between the number of days at liberty and distance between capture events for black rockfish recaptured by public fishers (regression-analysis, $\mathrm{df}=1, \mathrm{n}=147, \mathrm{p}=0.000, \mathrm{R}$-sq. $=15.8 \%$ ) with a general trend of increase in distance with days at liberty (Fig. 1). However, there is not a significant relationship between days at liberty and distance moved for black rockfish recaptured during CCFRP surveys (regression-analysis, $\mathrm{df}=1, \mathrm{n}=49, \mathrm{p}=0.313$, R-sq. $=2.2 \%$ ) (Fig. 2).

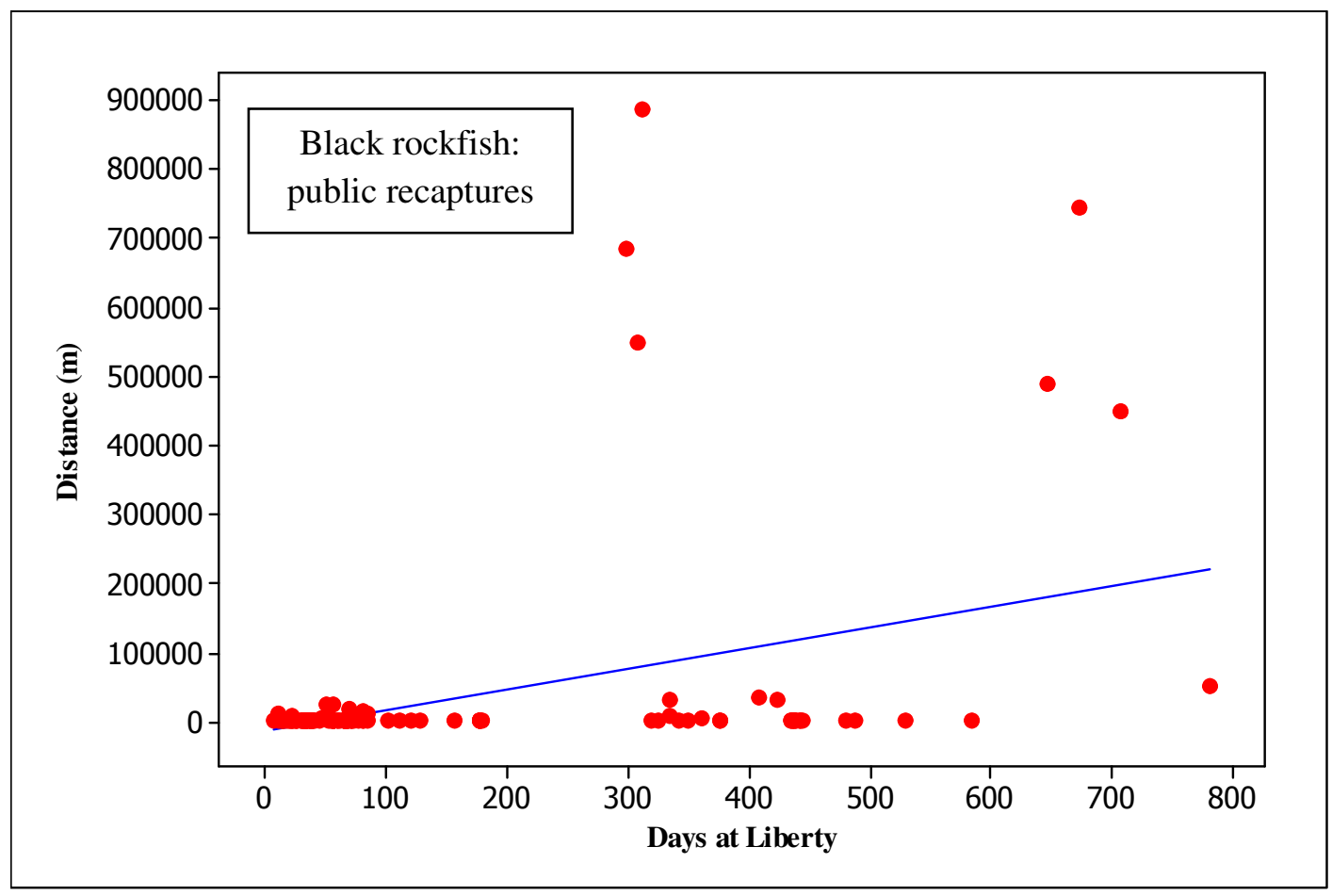

Figure 6. Scatterplot of days at liberty vs. distance between capture events (m) for black rockfish recaptured by public fishers. 


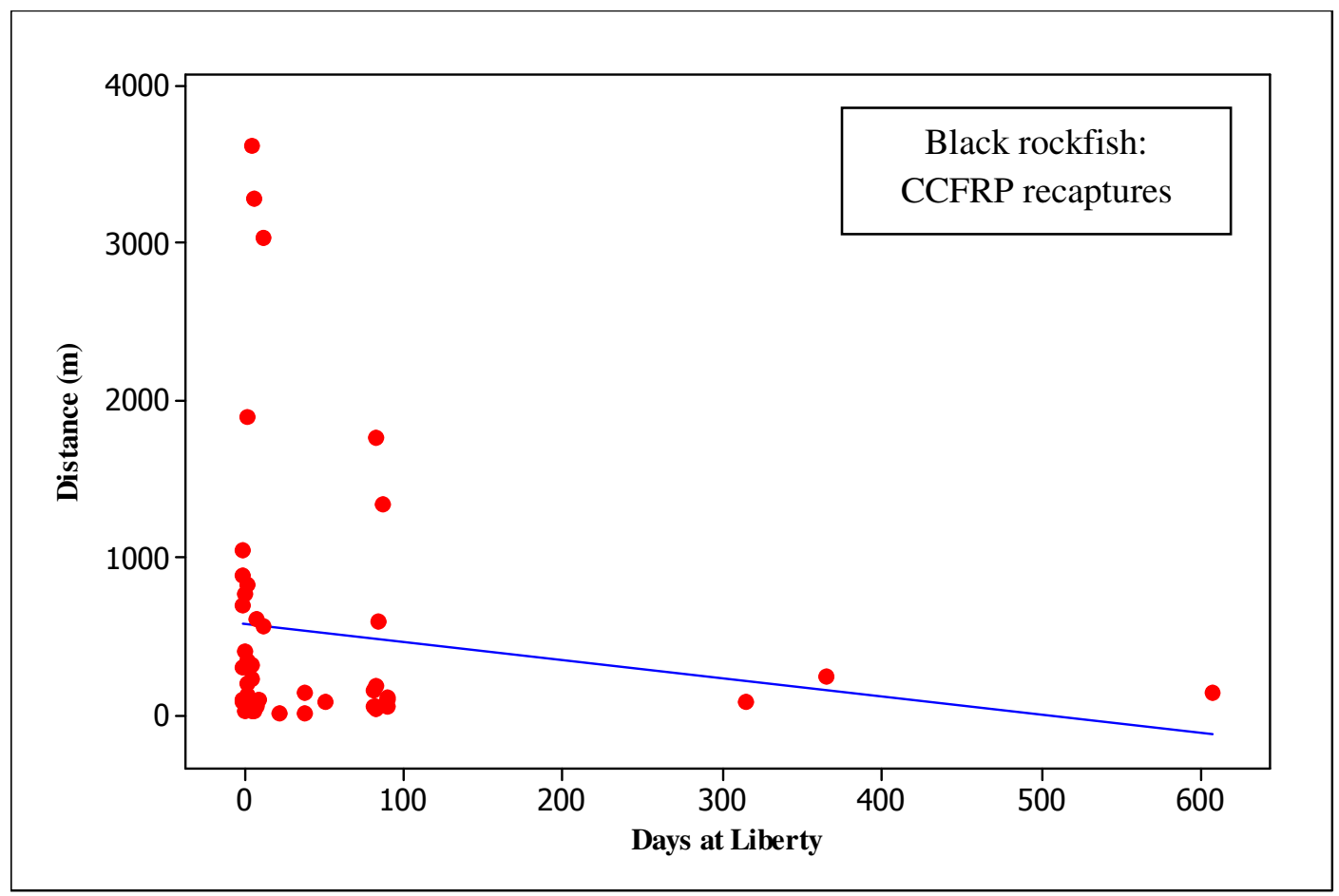

Figure 7. Scatterplot of days at liberty vs. distance between capture events $(\mathrm{m})$ for black rockfish recaptured during CCFRP surveys.

There is no evidence of a significant correlation between the distance moved between capture events and days at liberty for gopher rockfish recaptured by either public fishers (regression-analysis, $\mathrm{df}=1, \mathrm{n}=45, \mathrm{p}=0.844 \mathrm{R}$-sq. $=0.1 \%$ ) or on CCFRP surveys (regression analysis, $\mathrm{df}=1, \mathrm{n}=40, \mathrm{p}=0.071, \mathrm{R}$-sq. $=8.1 \%$ ). Scatterplots of both data sets are provided to demonstrate possible nascent trends (Figs. 3 and 4). 


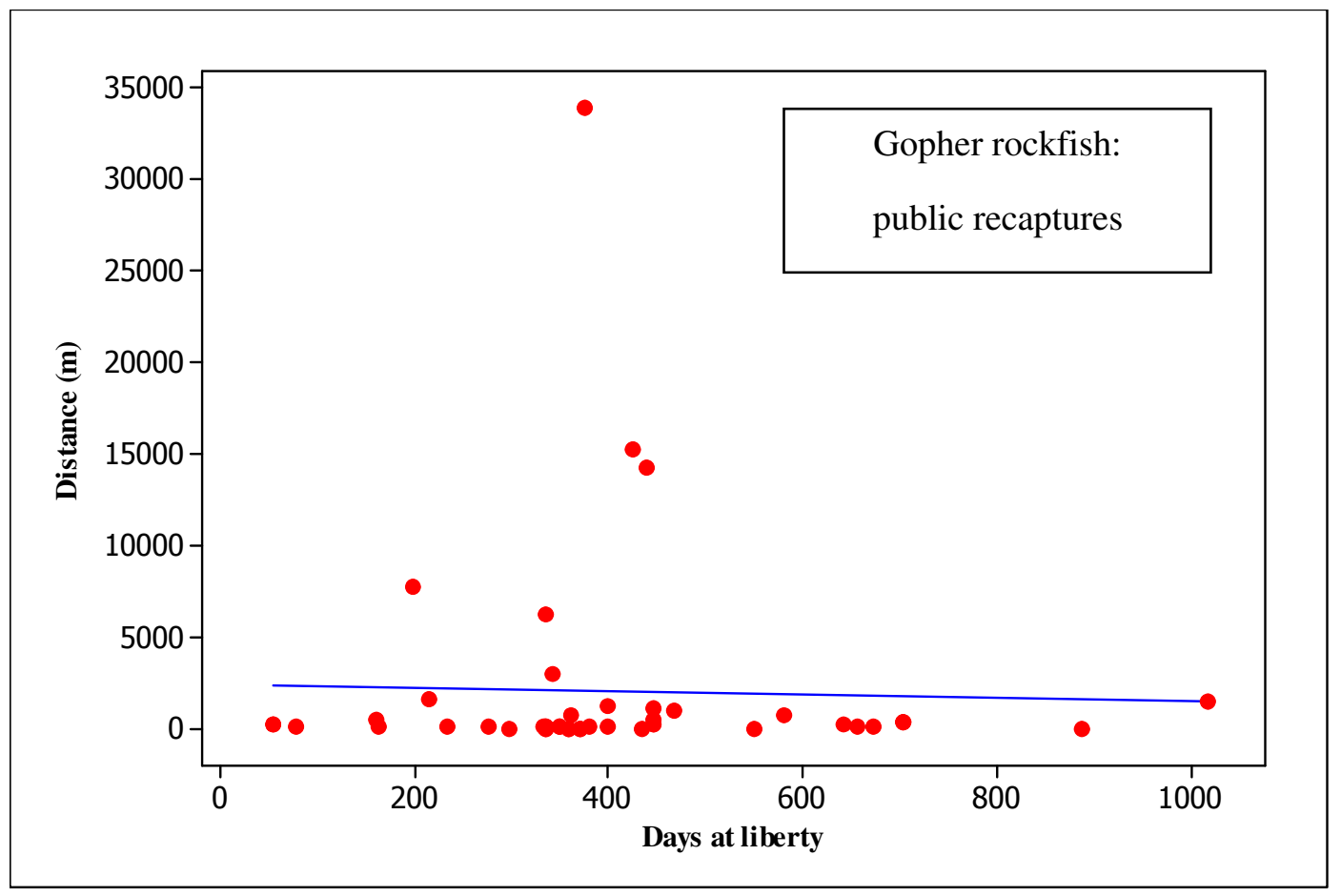

Figure 8. Scatterplot of days at liberty vs. distance between capture events (m) for gopher rockfish recaptured by public fishers.

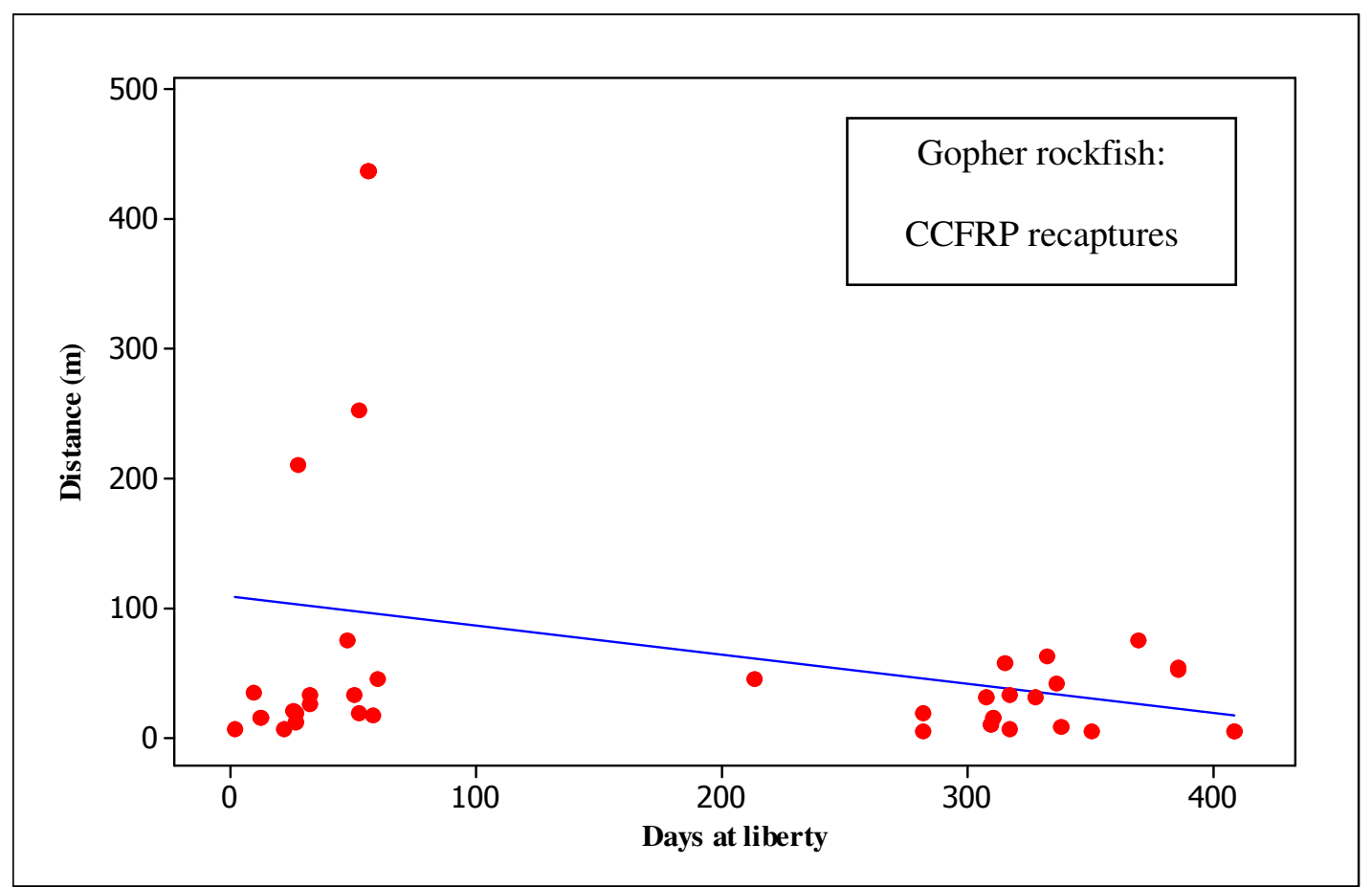

Figure 9. Scatterplot of days at liberty vs. distance between capture events (m) for gopher rockfish recaptured during CCFRP surveys. 
The numbers of days at liberty between capture events for blue rockfish was examined with the distances reported by public fishers and CCFRP surveys combined and did not yield a significant correlation (regression-analysis, $\mathrm{df}=1, \mathrm{n}=24, \mathrm{p}=0.343$, R-sq. $=4.1 \%$ ). A scatterplot of the data is provided in Fig. 5; of note is the farthestranging blue rockfish that moved over eight kilometers within one of the shortest number of days at liberty (27 days).

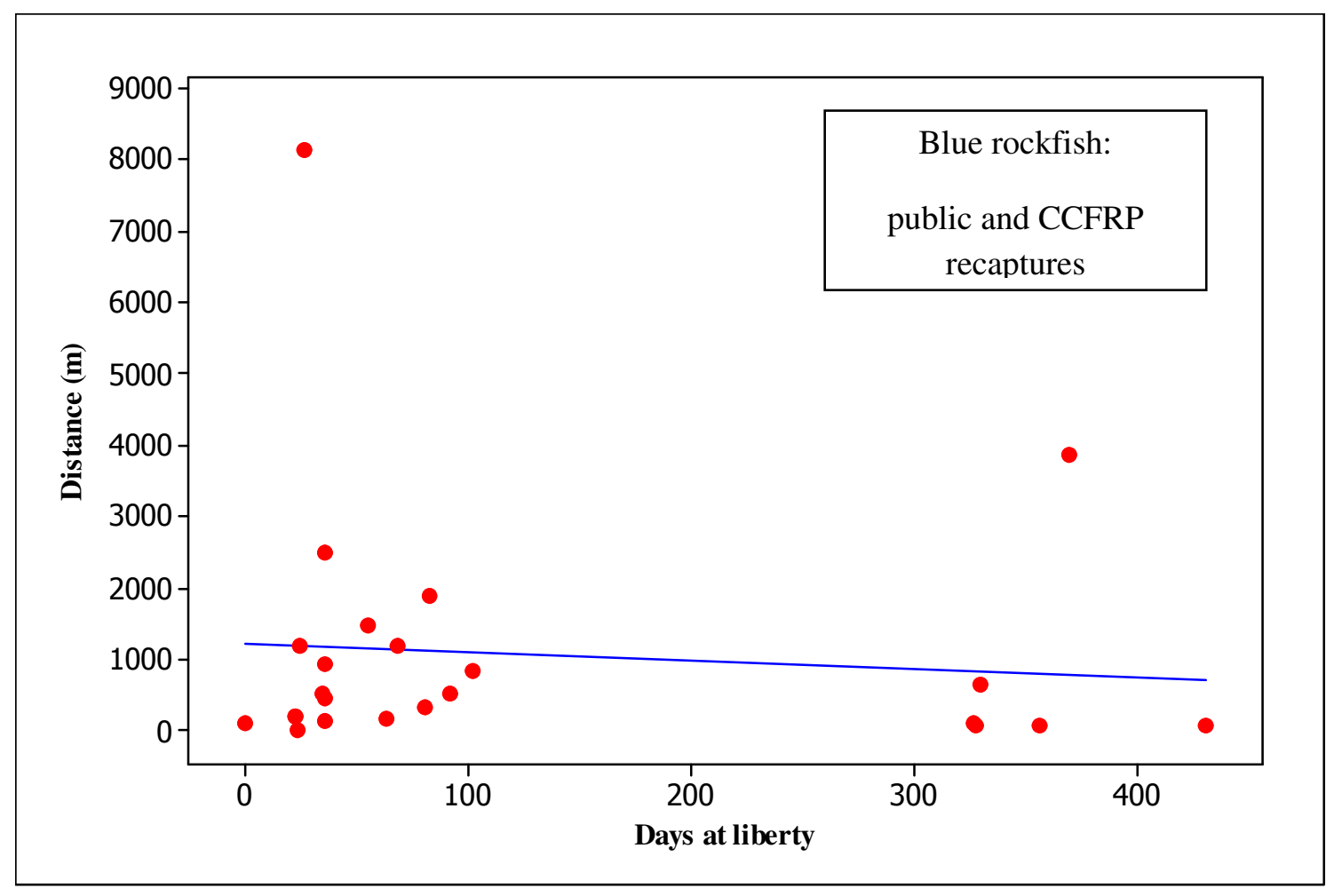

Figure 10. Scatterplot of days at liberty vs. distance between capture events (m) for blue rockfish recaptured by public fishers and during CCFRP surveys. 


\subsection{Fish Lengths}

Lengths of gopher, blue, and black rockfishes upon initial capture were examined to investigate whether a relationship exists between fish size and distance traveled between tagging events. This comparison did not consider the source of the recapture information, but pooled data from both public and CCFRP recapture data. There is no evidence of a significant relationship between fish length and the distance between tag and recapture for gopher rockfish (regression-analysis, $\mathrm{df}=1, \mathrm{n}=85, \mathrm{p}=0.756$, R-sq. $=$ $0.1 \%$ ), however a scatterplot of the data suggests a trend wherein fish of larger sizes travel greater distances (Fig. 6). The blue rockfish data does not demonstrate a significant correlation between fish size and distance traveled (regression-analysis, $\mathrm{df}=$ $1, \mathrm{n}=22, \mathrm{p}=0.359$, R-sq. $=4.2 \%)$ and no appreciable relationship can be detected in the scatterplot (Fig. 7).

Due to the wide range of distances traveled by black rockfish and a large departure from normality, I analyzed the lengths of the fish that moved $<10 \mathrm{~km}$ separately from those that moved $>10 \mathrm{~km}$. Neither group displayed evidence of a significant correlation between fish size and travel distance (regression-analysis for $<10$ $\mathrm{km}$ fish: $\mathrm{df}=1, \mathrm{n}=182, \mathrm{p}=0.084, \mathrm{R}$-sq. $=1.6 \%$; analysis for $>10 \mathrm{~km}$ fish: $\mathrm{df}=1, \mathrm{n}=$ 15, $\mathrm{p}=0.390, \mathrm{R}-\mathrm{sq} .=5.7 \%$ ). However, scatterplots for both groups indicate a tendency for larger fish to travel greater distance between capture events (Figs. 8 and 9). 


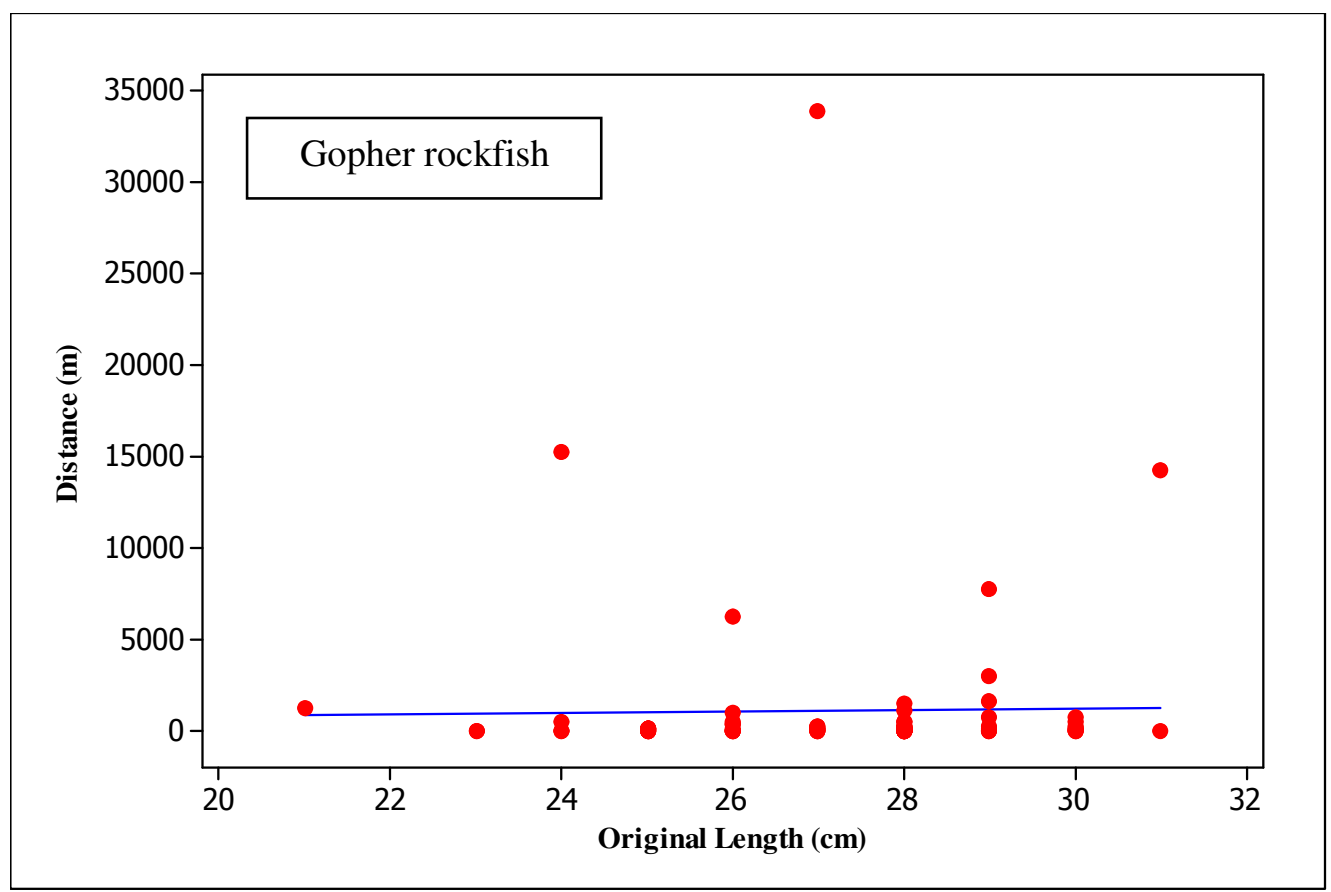

Figure 11. Scatterplot of distance between capture events vs. original length for gopher rockfish.

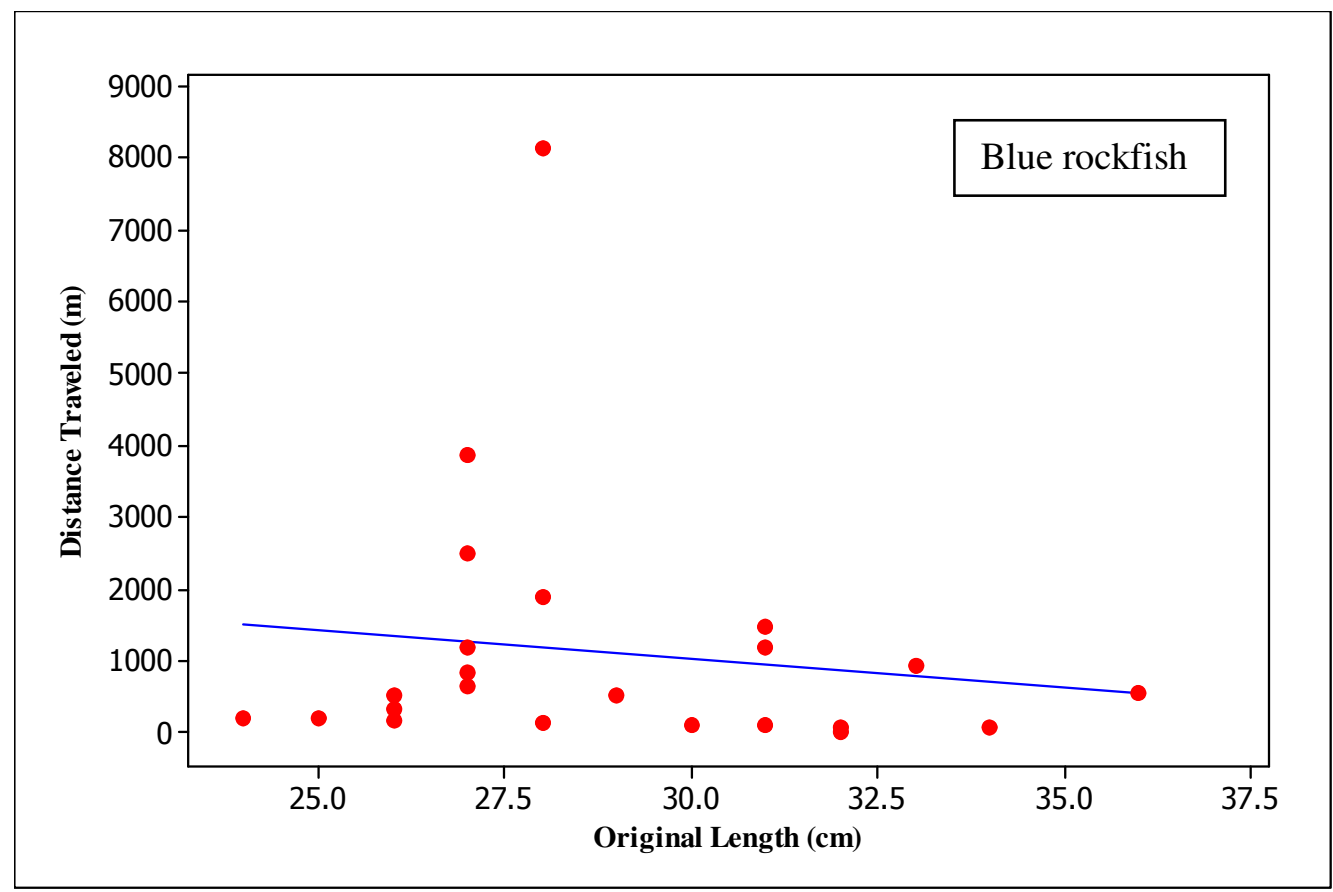

Figure 12. Scatterplot of distance between capture events vs. original length for blue rockfish. 


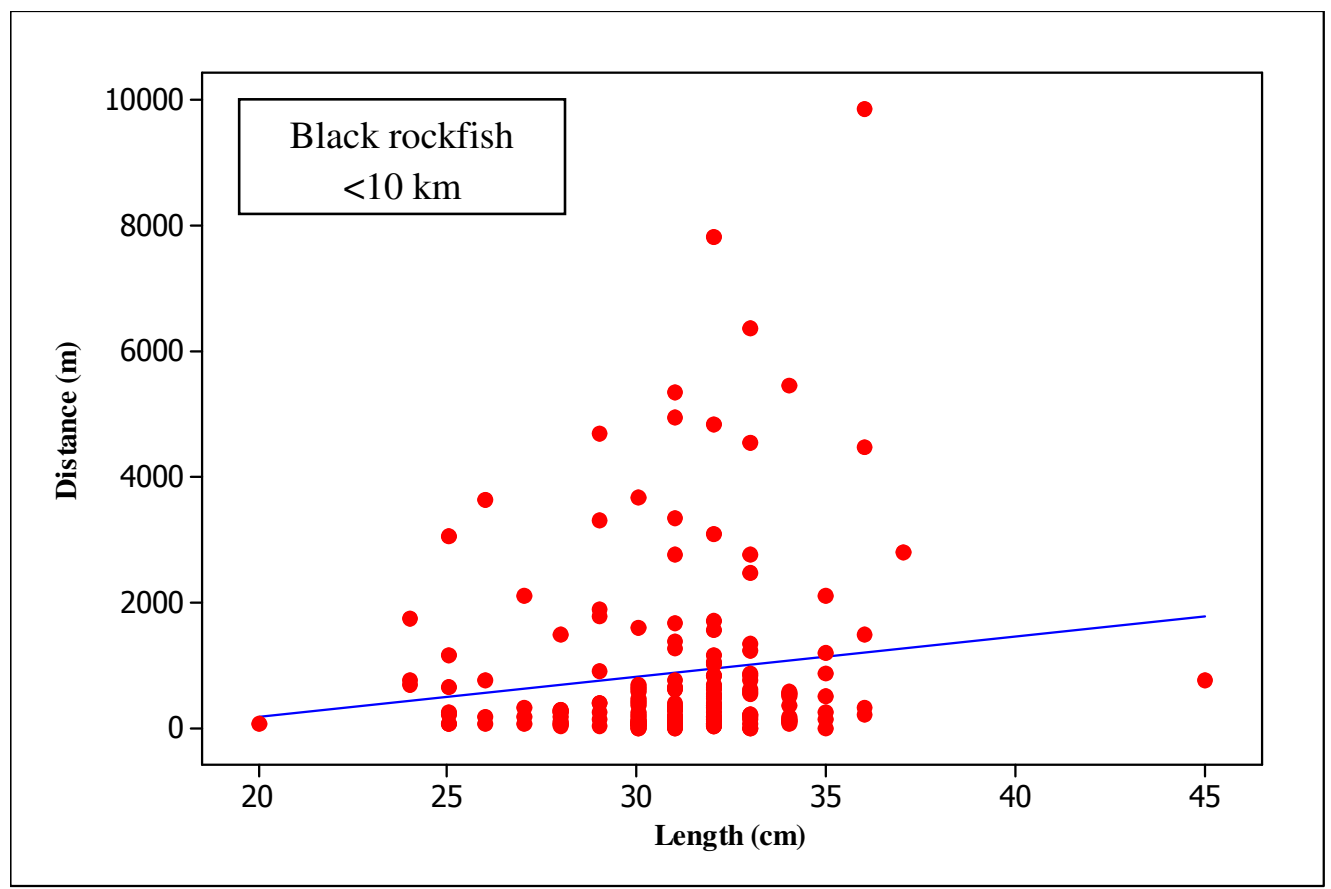

Figure 13. Scatterplot of distance between capture events vs. original length for all black rockfish that traveled $<10 \mathrm{~km}$.

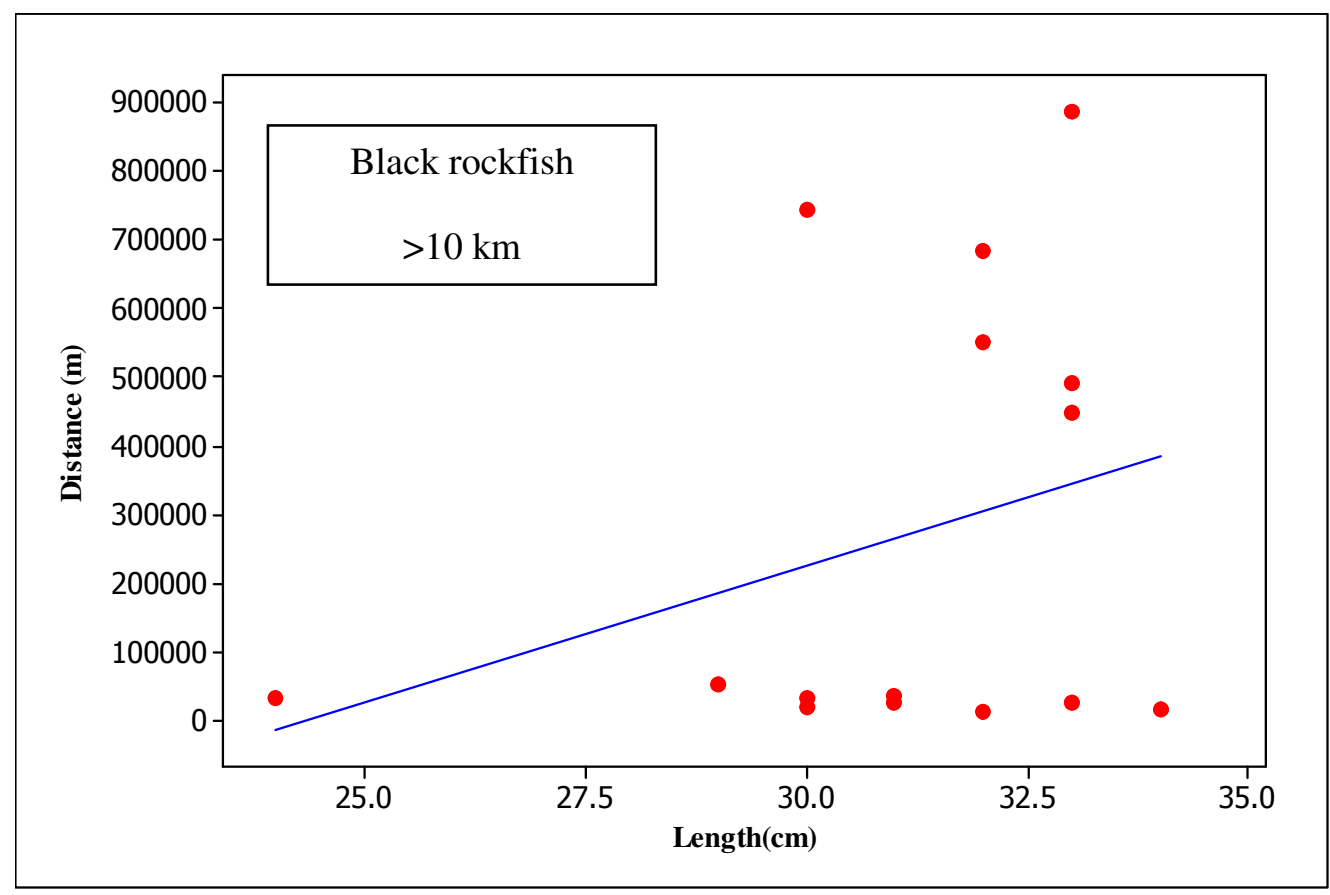

Figure 14. Scatterplot of distance between capture events vs. original length for all black rockfish that traveled $>10 \mathrm{~km}$. 


\subsection{Depth}

There is no evidence of a significant correlation between original capture depth and the distance each fish traveled until recapture for gopher or blue rockfishes (regression-analysis gopher rockfish, $\mathrm{df}=1, \mathrm{n}=83, \mathrm{p}=0.521$, $\mathrm{R}$-sq. $=0.5 \%$; analysis for blue rockfish, $\mathrm{df}=1, \mathrm{n}=22, \mathrm{p}=0.809, \mathrm{R}$-sq. $=0.3 \%$ ). While the scatterplot for gopher rockfish movement does not suggest a detectable pattern, that for blue rockfish implies a positive correlation between distance and original capture depth (Figs. 10 and 11, respectively).

When distances traveled by black rockfish are again partitioned between fish that moved $<10 \mathrm{~km}$ and those with movements $>10 \mathrm{~km}$ it is possible to observe a statistically significant correlation. There is evidence of a negatively-correlated relationship between distance moved and original capture depth among the 15 fish that moved $>10 \mathrm{~km}$ (regression-analysis, $\mathrm{df}=1, \mathrm{n}=15, \mathrm{p}=0.046, \mathrm{R}$-sq. $=27.3 \%$ ), with the farthest-moving fish originally having been captured in the shallowest depths observed (Fig. 12). In contrast, black rockfish that moved $<10 \mathrm{~km}$ do not exhibit a significant relationship between distance traveled and original capture depth (regression-analysis, $\mathrm{df}=1, \mathrm{n}=$ $179, \mathrm{p}=0.961, \mathrm{R}-\mathrm{sq} .=0.0 \%)$ 


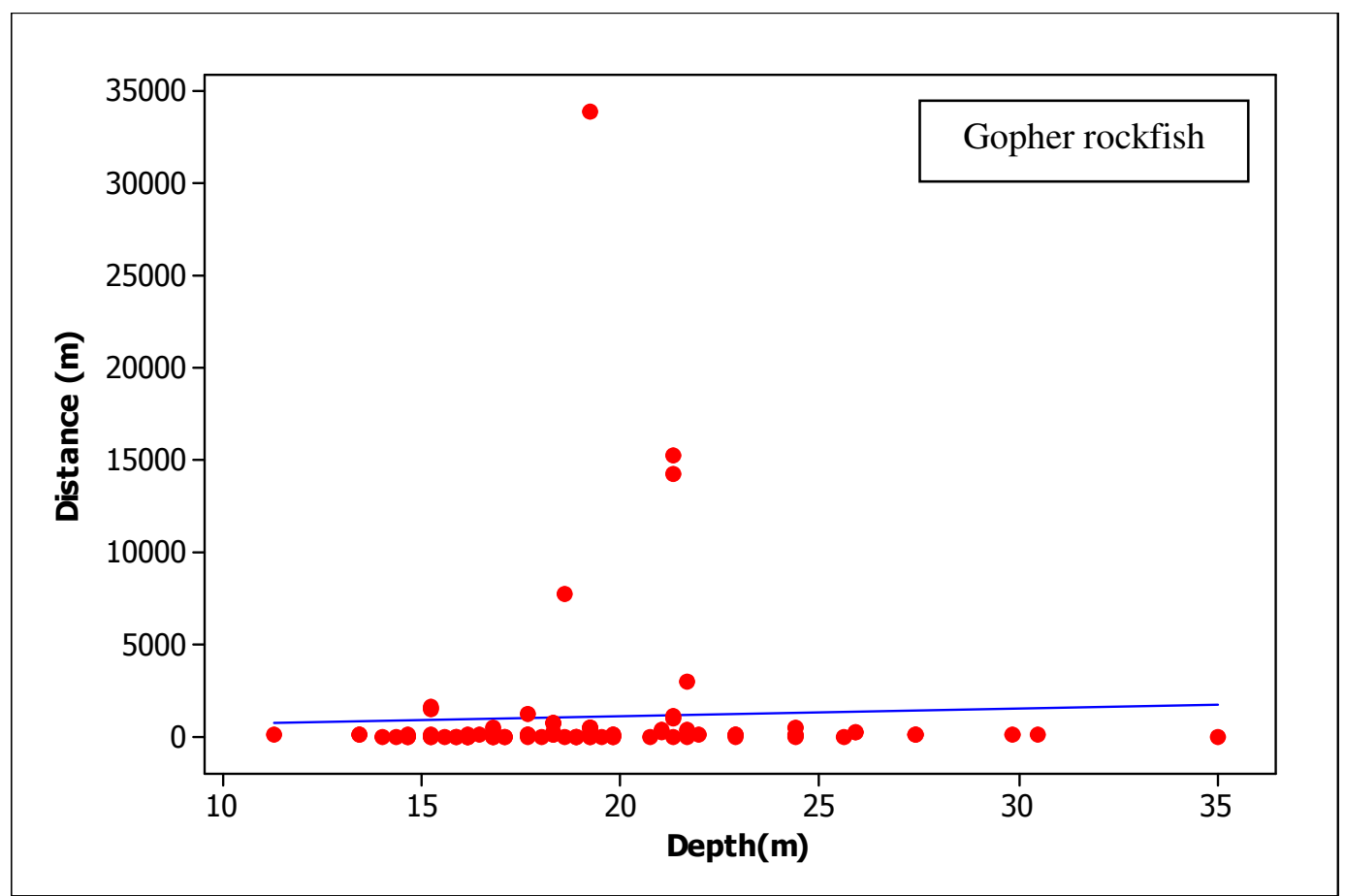

Figure 15. Scatterplot of distance traveled vs. original capture depth for gopher rockfish.

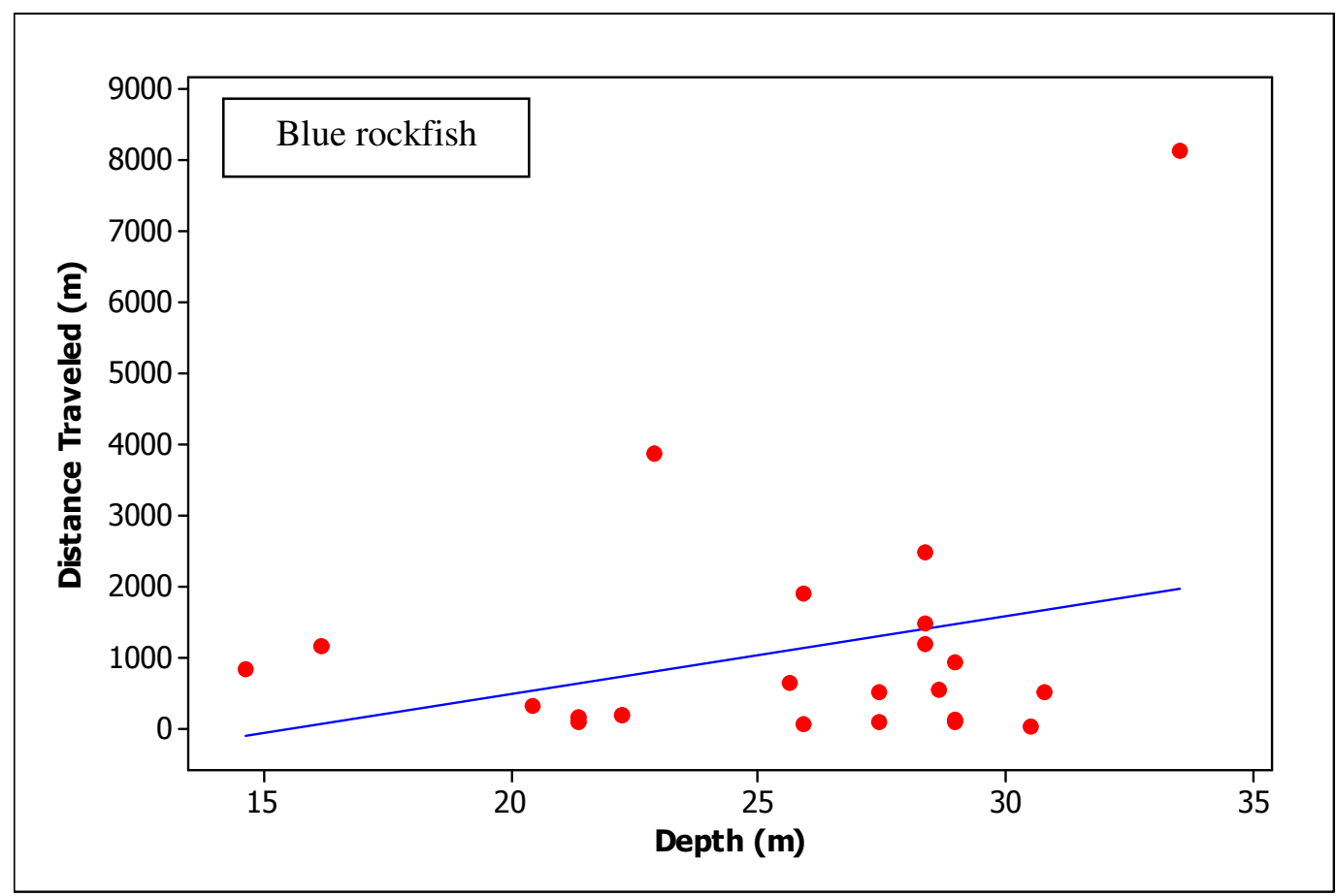

Figure 16. Scatterplot of distance between capture events and original depth for blue rockfish. 


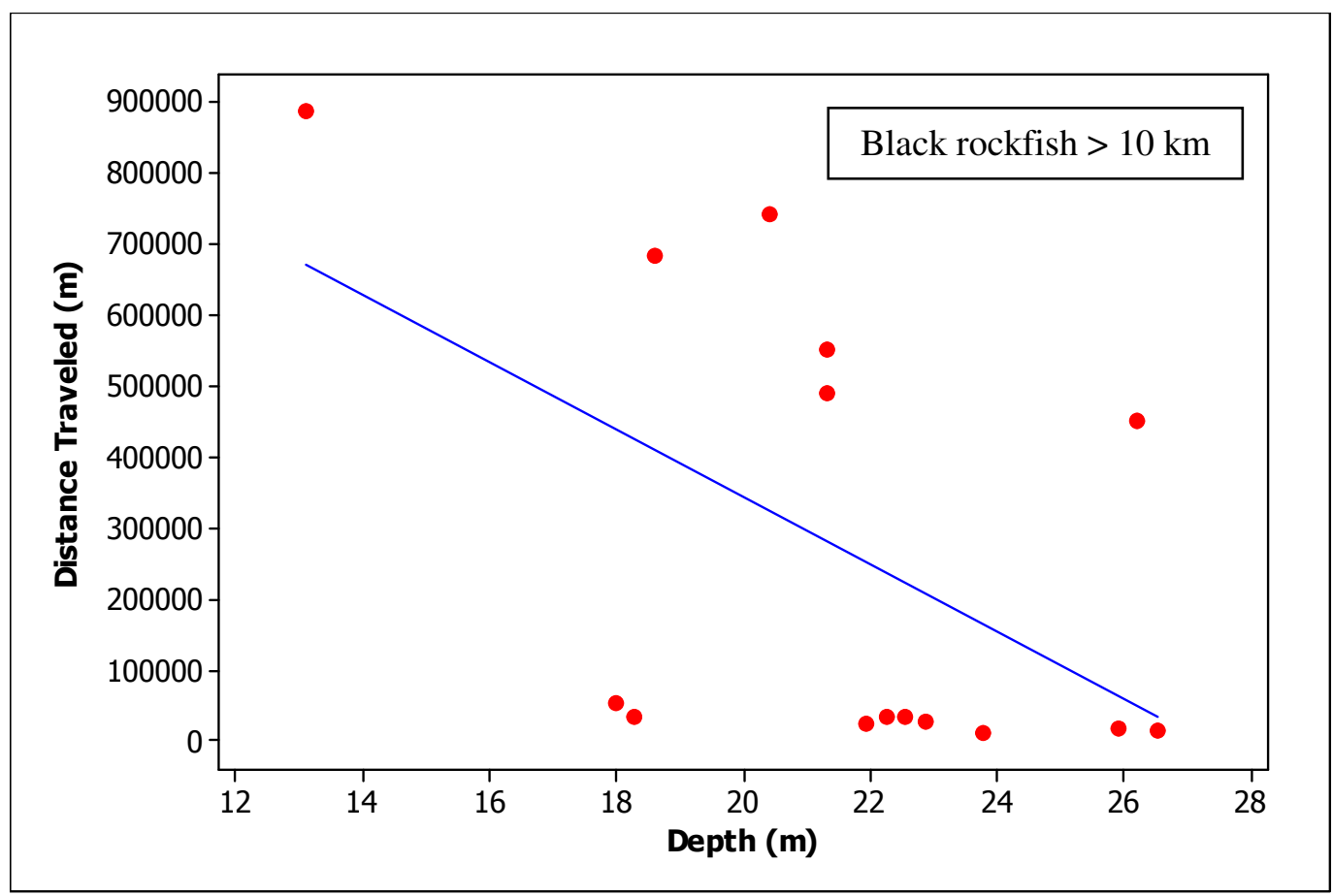

Figure 17. Scatterplot of distance between capture events and original depth for black rockfish.

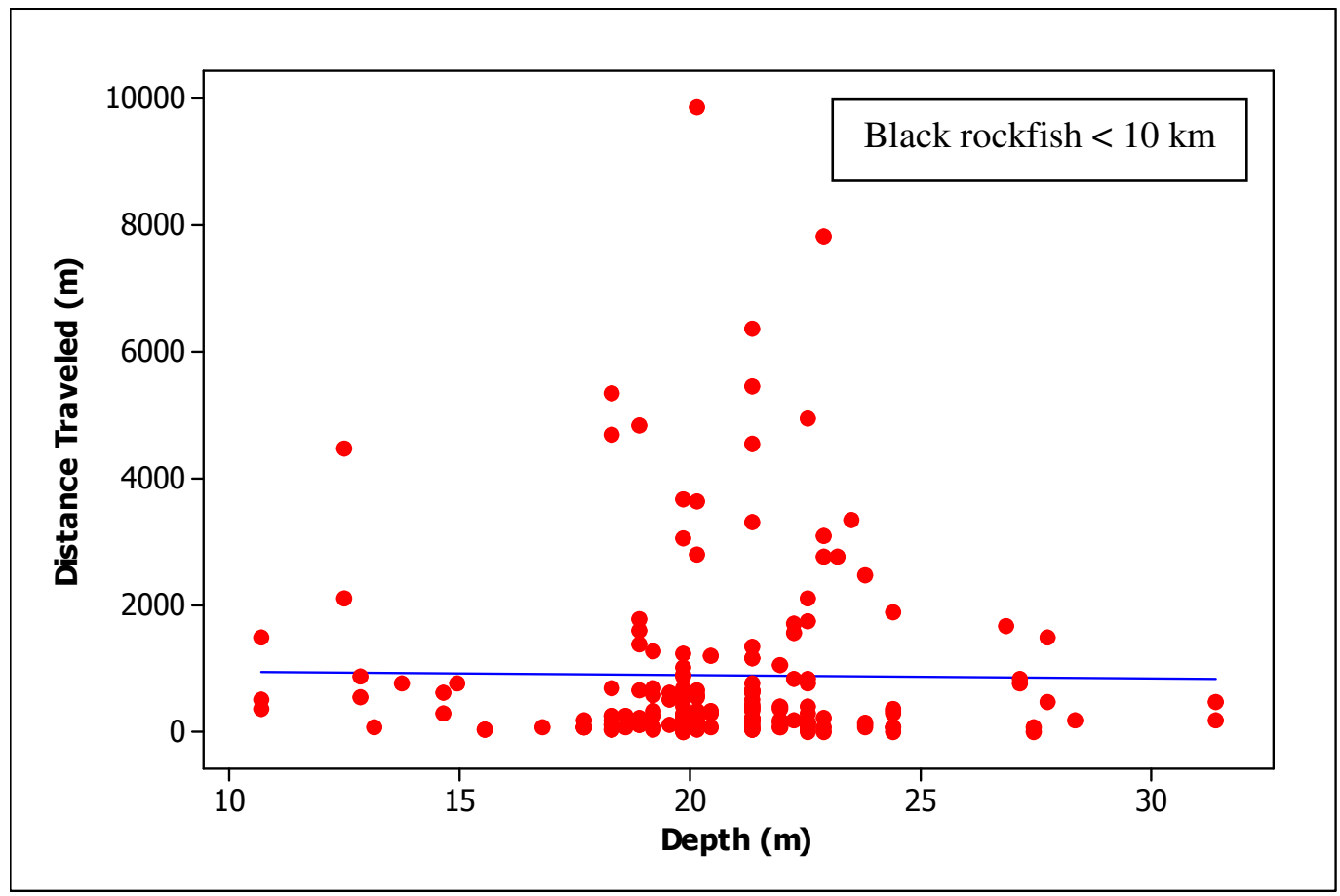

Figure 18. Scatterplot of distance traveled vs. original capture depth for black rockfish $<10 \mathrm{~km}$. 
A comparison of the original tagging depth versus recapture depth for the three species revealed a statistically significant difference for black and blue rockfishes but not for gopher rockfish. Black rockfish were recaptured in water $2.5 \mathrm{ft}$ deeper, on average, than their original capture depth (paired t-test, $\mathrm{n}=127, \mathrm{p}=0.035$ ) and blue rockfish were recaptured $8 \mathrm{ft}$. shallower, on average (paired t-test, $\mathrm{n}=15, \mathrm{p}=0.047$ ). Gopher rockfish were recaptured, on average, $0.33 \mathrm{ft}$. shallower than their original capture depth (paired ttest, $\mathrm{n}=101, \mathrm{p}=0.838$ ).

\subsection{Handling Conditions}

I considered whether the condition of gopher, blue, and black rockfishes upon initial capture and tagging affected the distance a fish traveled before being recaptured again. The conditions recorded for each fish during CCFRP surveys were based on a visual assessment of the fish and included its physical state as well as the type of handling it received while at the surface. The categories recorded included eye damage, venting by hypodermic needle, hook damage, predation by a marine mammal or another fish, use of a descending device, a fish floating after being released, or a fish mortality. There is no evidence of a relationship between fish condition and distance between capture events for gopher, blue, or black rockfishes (gopher ANOVA, df =6, n =87, p = 0.833; blue ANOVA, $\mathrm{df}=3, \mathrm{n}=23, \mathrm{p}=0.241$; black ANOVA, $\mathrm{df}=1, \mathrm{n}=14, \mathrm{p}=$ $0.465)$. 


\subsection{Catch-Per-Unit-Effort (CPUE)}

In order to examine whether fish abundance at the capture site exhibited an effect on travel distance for gopher, blue, and black rockfishes, I analyzed the catch-per-uniteffort (CPUE), a proxy for fish abundance, at each site (MPA or reference) as an average per sampling season. Hook-and-line and trap gear types were considered separately with fish-per-angler-hour units used for the former and fish-per-trap-hour, the latter. All fishes that traveled $>10 \mathrm{~km}$ were considered separately in order to allow for greater resolution in a potential relationship. However, regression analyses showed no evidence for a significant relationship between distance traveled and CPUE for either gear type examined (regression-analysis $<10 \mathrm{~km}$ hook-and-line, $\mathrm{df}=1, \mathrm{n}=60, \mathrm{p}=0.632$, R-sq. $=$ $0.4 \%$; regression analysis $>10 \mathrm{~km}$ hook-and-line, $\mathrm{df}=1, \mathrm{n}=6, \mathrm{p}=0.241$, $\mathrm{R}$-sq. $=32.1 \%$; regression-analysis trap, $\mathrm{df}=1 \mathrm{n}=43, \mathrm{p}=0.909, \mathrm{R}$-sq. $=0 \%$ ). Scatterplots are provided in order to appreciate potential emerging trends (Figs. 14, 15, and 16). 


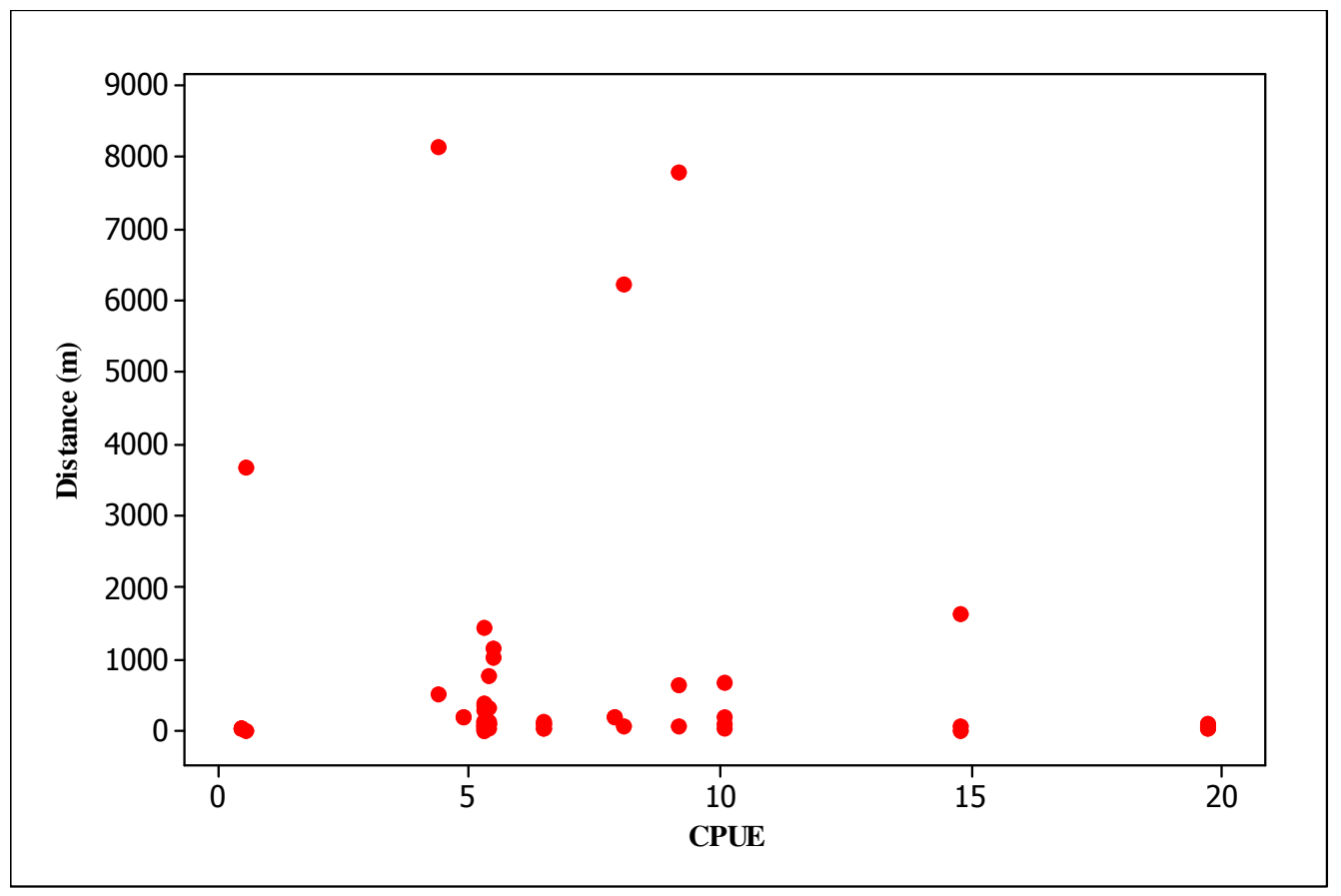

Figure 19. Distance vs. CPUE for gopher, blue, and black rockfishes captured during hook-and-line surveys that traveled $<10 \mathrm{~km}$ (CPUE units are fish-per-anglerhour).

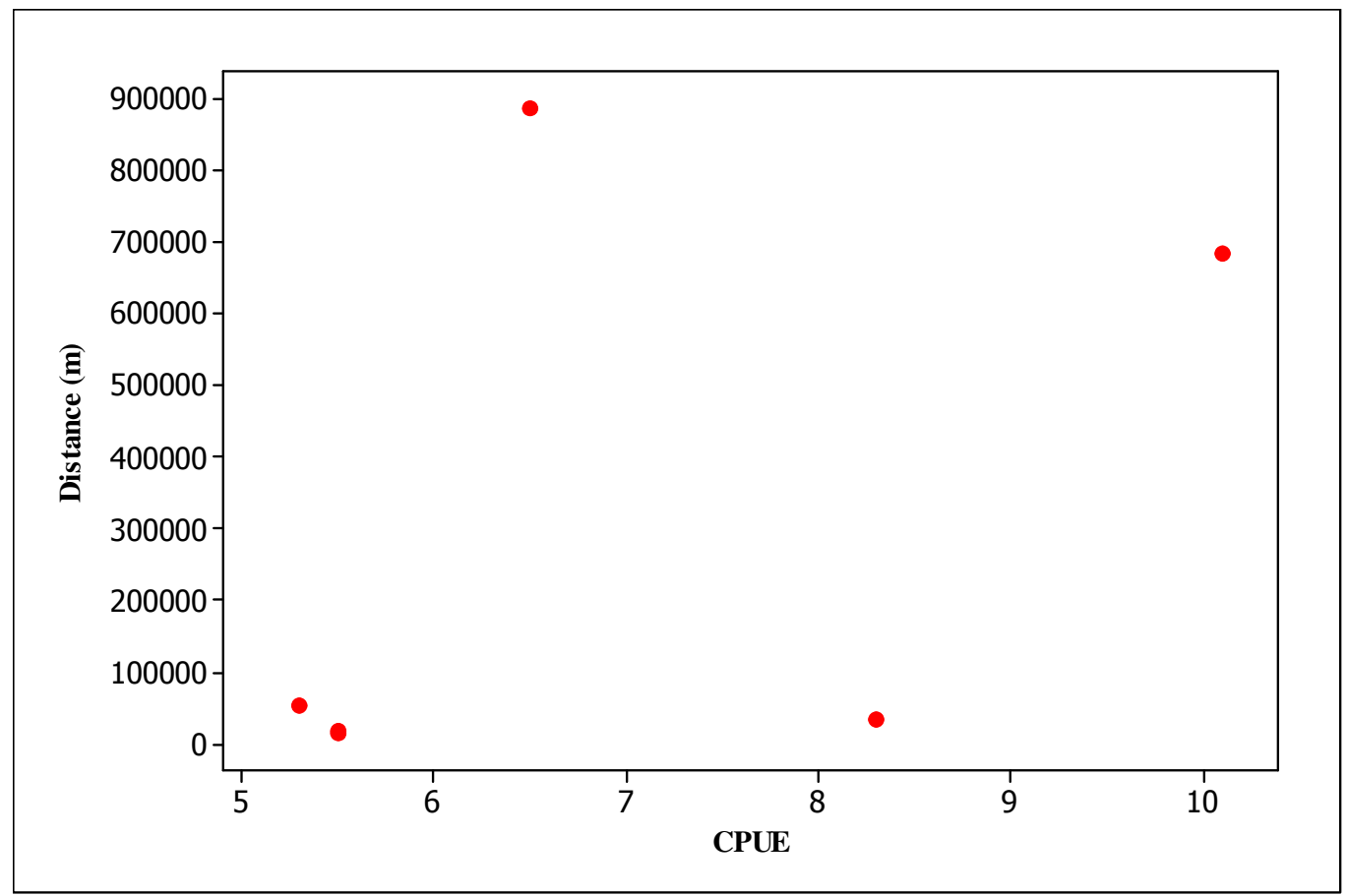

Figure 20. Distance vs. CPUE for gopher, blue, and black rockfishes captured during hook-and-line surveys that traveled $>10 \mathrm{~km}$ (units are fish-per-angler-hour). 


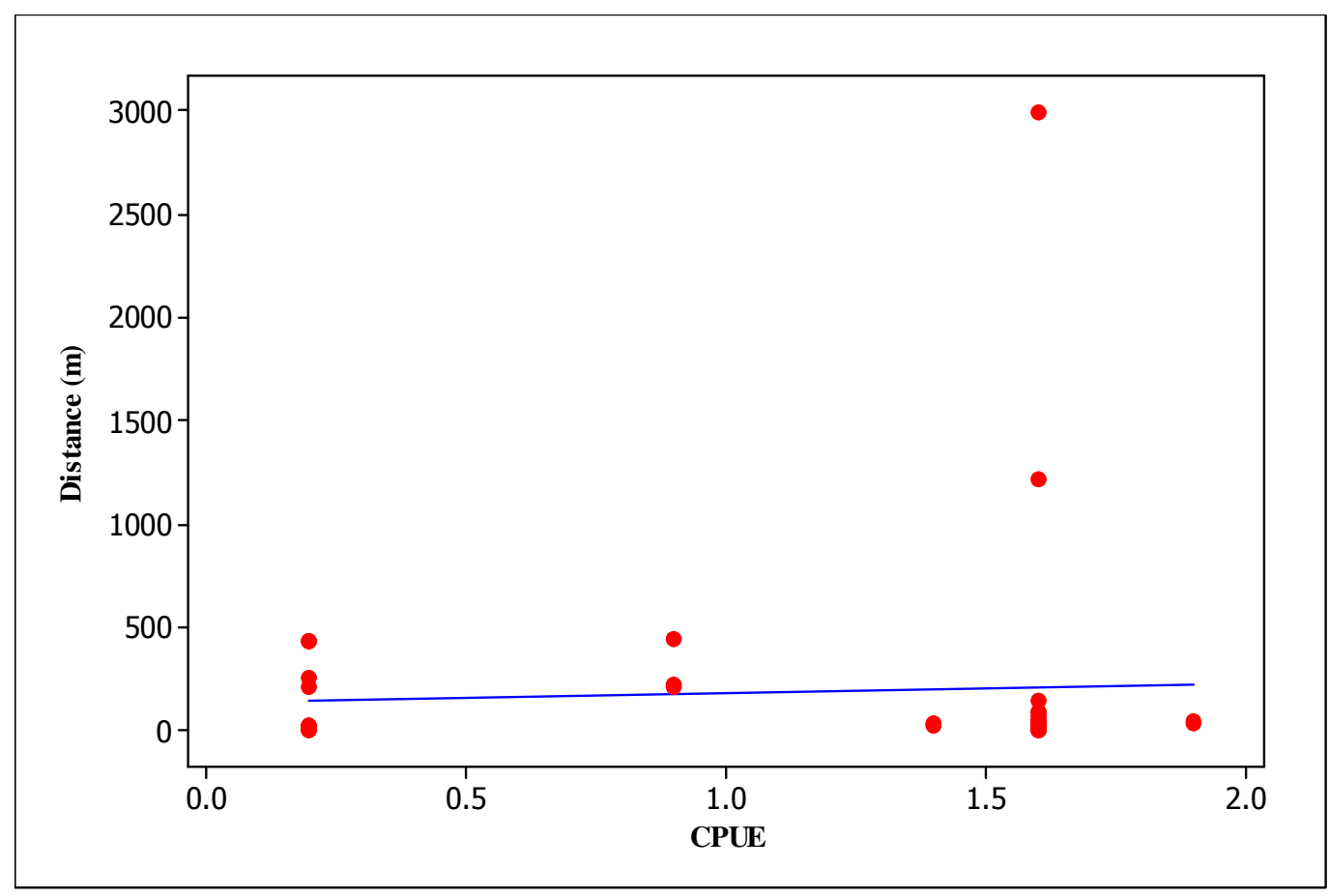

Figure 21. Distance vs. CPUE for all gopher, blue, and black rockfishes captured in traps (CPUE units are fish-per-trap-hour). 


\section{Chapter 4. Discussion}

Due to the emerging widespread utilization of marine reserves throughout the world as a tool for fisheries conservation and management, a more complete understanding of fish movement has been sought after to facilitate the proposal and MPA design process. Fish species throughout the nearshore environment of the eastern Pacific exhibit an array of movement behavior, including varied space use, rates of movement, home range size, and territoriality. The biotic and abiotic factors governing species' movements are not perfectly elucidated, and much inter- and intraspecific variation exists.

The objectives of this study were to explore movement patterns of nearshore temperate reef-fish species along California's central coast and to relate those movement behaviors to the region's current marine reserve network configuration. Specifically of interest was the ability to predict which species are likely to be protected within a marine reserve and accrue the desired benefits. Over 37,000 fishes were tagged from 2005-2009 throughout the central coast region and 476 tagged fish from 14 species were recaptured as of June 25, 2010. Information, including location coordinates, date, gear type, fish length, and depth provide insight into the characteristics of reef fish movements along the central coast.

Although our overall recapture rate $(1.3 \%)$ is low in comparison to the expected rate (3-10\%) for tag-and-recapture studies (Lowe \& Bray, 2006), our results are based on species sample sizes comparable to or larger than those found within the literature. (Griffiths \& Wilke, 2002; Mathews \& Barker, 1983; Holland et al., 1993; Stanley et al., 1994; Pearcy, 1992). Our results corroborate their findings as well as provide new 
perspectives which will prove useful in future MPA design processes. The observation of over $75 \%$ of recaptured fishes within one kilometer of the initial tagging site is in accordance with studies that suggest temperate shallow-reef fishes make mostly smallscale movements (Love, 1980). However, the proportion of fishes of various species within this study that were recaptured on the order of tens and hundreds of kilometers away from the initial tagging site present other dynamics of fish behavior that merit attention as well.

I considered a range of factors that showed potential for shaping movement behavior for all recaptured fishes, but focused the majority of the analysis on the three species for which we received most recapture data (black, gopher, and blue rockfishes). Analyses included examination of geographic variation in fish movements along the central coast, source of recapture data, gear type, days at liberty between capture events, fish lengths, initial capture depth, fish handling condition, and fish abundance at the initial capture site. I also considered the frequency of border-crossings fish made across reserve boundaries and the general habitat profile of recapture locations. The direction of far-ranging movements was also investigated.

For gopher and black rockfish, appreciable trends emerged in travel distances depending upon whether fish were recaptured by public fishers or on CCFRP surveys. Additionally, the degree of gopher rockfish movement differed depending on the initial capture gear type (hook-and-line or trap). Black rockfish were observed to move the greatest distances in this study and showed a positive correlation between the number of days at liberty and distances traveled when recaptured by public fishers. However, this relationship does not exist for black rockfish recaptured during CCFRP surveys, nor does 
it exist for gopher or blue rockfishes. There was no evidence of a statistically significant relationship between fish length and distance moved for any of the three top recaptured species; however, the longest-distance travelers were among the largest fish for gopher and black rockfish. The black rockfish that traveled furthest from the tagging site were those originally captured in the shallowest water, as evidenced in the significant negative correlation between distance and depth. The same trend is not evident for gopher or blue rockfishes, or for black rockfish that traveled less than ten kilometers. Initial capture depth for black rockfish $($ mean $=66.3 \mathrm{ft})$ and blue rockfish $($ mean $=81.2 \mathrm{ft})$ were significantly different than the mean recapture depths for both $(68.8 \mathrm{ft}$ and $73.1 \mathrm{ft}$, respectively). However, this relatively small change in depth between capture events suggests that there is high depth predictability for both species. The difference between initial capture depth for gopher rockfish (mean $=64.0 \mathrm{ft}$ ) was not significantly different from the depth at recapture (mean $=63.7 \mathrm{ft}$ ), similarly exemplifying the high depth and/or habitat specificity for the species. Travel distance between initial tagging and recapture locations was not significantly correlated with the handling condition of each fish or with fish density. 
Table 2. Summary of results for each factor analyzed among the three species with most recapture information, where ' $X$ ' represents a significant relationship to movement.

\begin{tabular}{lccc}
\hline \multicolumn{1}{c}{ Factor } & Gopher Rockfish & Black Rockfish & Blue Rockfish \\
\hline $\begin{array}{l}\text { Geographic } \\
\text { variation }\end{array}$ & $\times$ & & \\
$\begin{array}{l}\text { Source of recapture } \\
\text { information }\end{array}$ & $\times$ & $\mathrm{n} / \mathrm{a}$ & $\mathrm{n} / \mathrm{a}$ \\
Gear Type & & $\times$ & \\
Days at Liberty & & & \\
Fish Length & & $\times$ & \\
Depth & & \\
Handling Condition & & \\
CPUE & & & \\
\hline
\end{tabular}

\subsection{Geographic Variability}

There is evidence of a gradation of spatial structure in marine ecosystems along the west coast of North America resulting in regional biological differences among nearshore groundfish (Gunderson et al., 2008). Latitudinal shifts in populations due to atmosphere-ocean processes, such as wind stress and current patterns, are also important factors in shaping these differences. Using data from only one portion of a species' range to make generalizations on the status of the entire stock can give misleading inferences, and current fisheries management increasingly considers regulations structured on scales of one to tens of kilometers for shallow water species (Francis et al., 2009). 
I examined the movement of recaptured fishes partitioned throughout three regions of the central coast in order to determine if there were distinct patterns of behavior at a relatively small spatial scale. California's Department of Fish and Game considers the area along the coast between Cape Mendocino ( $\left.40^{\circ} 10^{\prime}\right)$ and Point Conception ( $\left.34^{\circ} 27^{\prime}\right)$ the 'Central' groundfish management area. It is further divided from north to south into four uniquely managed sub-areas based on the major capes within the region's boundaries: Point Arena, Pigeon Point, and Lopez Point. When I partitioned our fish movement data corresponding to these geographical and management boundaries, no appreciable differences were detected among the regions. This indicates a general continuity of dispersal behavior in the central coast study region for the nine species examined (cabezon, lingcod, and black, blue, brown, canary, vermilion, yellowtail, and gopher rockfishes), and perhaps a continuity across each species' entire range.

\subsection{Movement Behavior}

\subsubsection{Black Rockfish}

The few studies that have examined black rockfish movement found relatively high mobility in comparison to other rockfish species. In these studies a portion of individuals traveled on the order of hundreds of kilometers (Mathews \& Barker, 1983; Love et al., 2002). My observation of a significant correlation between travel distance and the number of days at liberty for black rockfish recaptured by public fishers suggests that far-ranging dispersal behavior is consistent for the species. However, the dispersal of 
black rockfish away from their tagging site correlated with time might simply indicate random diffusion or dispersal, governed only by oceanographic processes (McClanahan \& Mangi, 2000). All six of the large-scale movements (>440 km) made by black rockfish in this study occurred in a northerly direction, possibly with the aid of currents advected along the coast. Random diffusion is not a likely mechanism, as suggested by the northward trajectory of movement away from the southern end of the species' range and the limited number of individuals observed to do so.

\section{Black rockfish recaptured during CCFRP surveys demonstrated localized} movements and did not show a correlation between travel distance and the number of days at liberty. Although a portion of these fish traveled 2-4 km from the tagging site, the observation likely represents a scenario of a larger proportion of more residential fish that are moving about local rock outcrops (Love et al., 2002). It is possible that a small percentage of fish move much greater distances than their conspecifics as an evolutionary response enabling populations to respond to localized disasters and to provide genetic mixing of metapopulations (Starr \& Green, 2007). The duality of behavioral types of recaptured black rockfish in the current study could also be explained by a genetic polymorphism with regard to movement, including a larger resident population and smaller, far-ranging components (Attwood \& Bennett, 1994).

Juvenile and sub-adult black rockfish are usually found in water less than 65 feet and inhabit deeper water as they grow (Love et al. 2002). In the present study the black rockfish that traveled farthest $(>10 \mathrm{~km})$ were originally captured in the shallowest depths and were all well below the length at 50\% maturity for the species (Echeverria, 1987). Various studies have shown that black rockfish are most territorial during the 
reproductive season, with larger males chasing smaller individuals and thus limiting their territories (Shinomiya and Ezaki, 1991; Harada, 1962). It is possible that the fish we sampled are sub-adults and that some were chased away by larger individuals from an area saturated in territories. The younger and smaller conspecifics might travel within the metapopulation range to ensure future reproductive success as per the social and mating structure for the species (Mitamura et al., 2005). It would be of interest to utilize diver observations in order to determine if territoriality and dispersal behavior is different between male and female black rockfish.

\subsubsection{Gopher Rockfish}

Observations indicate that gopher rockfish have a duality of behavioral types similar to that observed in black rockfishes, but consistent far-ranging movements have not been found in previous studies (Hoelzer, 1988; Matthews, 1986; Larson, 1980a-c). In contrast to the far-ranging movements made by black rockfish, which were on the order of hundreds of kilometers, the longest travel distances made by gopher rockfish were all less than $35 \mathrm{~km}$. The small subset $(5 \%)$ of recaptured gopher rockfish that moved over 6 $\mathrm{km}$ counters the previously accepted perception of limited space usage for the species. Gopher rockfish have been found to confine their activities to specific, small areas in rocky holes or crevices, with home ranges often consisting of a primary shelter and a larger exposed area of 2-10 m² (Larson, 1980a). Matthews (1986), however, observed recaptured gopher rockfish on a reef $1.2 \mathrm{~km}$ from the tagging site, which at the time of the study represented some of the longest known movements for the species. 
The lack of a significant relationship between travel distance and days at liberty suggests that when a fish left the tagging site, its trajectory was not random but rather directed towards a particular new locality. The impetus for such directed movement can possibly be explained by the species' social behavior. Gopher rockfish have been observed to be aggressive and extremely territorial, with border disputes between fish often resulting in chases and biting (Larson, 1980a). Fish density is thought to limit the number of gopher rockfish at a site, as determined by substrate complexity and shelter availability (Larson, 1980b). The fish that moved away from the tagging site in the current study likely were not territory holders and therefore, would have been in pursuit of shelter and a space in which to feed. Larson's (1980b) lab and field studies showed that there is no annual or seasonal reestablishment of territories, and that a fish may even maintain its territory for the duration of its life. Fish without adequate shelter space and an adjoining feeding ground would be forced to seek out these fundamental requirements, which could be many kilometers away.

Larson (1980a) found the size of a gopher rockfish's home range to increase with fish length and depth, due to the implicit higher energetic needs of larger fish and lower prey availability with depth. Although there was no evidence of a significant relationship between distance traveled and fish length, Figure 11 shows that some of the farthestranging fish were among the largest in size. Such individuals would require larger feeding territories as a result of their higher metabolic needs and might leave a site in pursuit of a more productive location if necessary. Conversely, smaller fish tend to be non-territorial "floaters" and are found to be frequently chased by other fish (Larson 1980a). Two of the gopher rockfish that moved over $6 \mathrm{~km}$ were among the smallest fish 
measured and could possibly represent a scenario of movement induced by aggressive interactions.

\subsubsection{Blue Rockfish}

The movements observed for blue rockfish in the current study are similar to patterns encountered in other studies of the pelagic, schooling species; however, a home range size estimate has not been made thus far (Lowe \& Bray, 2006). Although some large-scale movements up to $43 \mathrm{~km}$ have been noted in previous studies, the majority of observed movements have been less than one kilometer (Love et al., 2002; Hartmann, 1987). Miller and Geibel (1973) found juvenile blue rockfish to exhibit less movement from a shallow kelp bed habitat $(60 \mathrm{~m})$ than from deeper reefs $(1.3 \mathrm{~km})$. Their findings suggest that habitat type and depth affect dispersal and possibly home range size. Our data corroborates such findings in that the farthest-traveling fish were caught in the deepest waters, however not with a statistically significant relationship (fig. 16). Blue rockfish are found in kelp beds and deeper water, therefore permitting both behavioral types to occur in the nearshore environment (Love et al., 2002)

\subsection{Source of Tag Return Information}

Technological advancements in the methodology for determining fish movement patterns, especially remote sensing techniques, have allowed for greater spatial and temporal resolution and thus a more detailed understanding of site fidelity and depth preferences (Lowe et al., 2009). However, the benefits of traditional tag-and-recapture studies include the ability to obtain a large sample size of marked fishes and the capacity 
to observe movement patterns over long time periods and distances. Such benefits render these types of studies consistently valuable and cost effective. Certain limitations of tagand-recapture methods must be considered in the interpretation of their movement data, such as fisher compliancy to report tags (non-reporting), accuracy of reported data, tag shedding, tag-induced behavioral changes or mortality, and the likelihood that fishers will encounter tagged fishes (Green \& Matlock, 1983; Smith \& Scharf, 2009; Nichols et al., 1991; Love, 1980).

The significantly larger size range of fish movements encountered by public fishers compared with those observed by our own CCFRP surveys for black and gopher rockfishes suggests that observable fish movements may be dependent on utilized fishing locations. The inherent freedom of public fishers to disperse throughout the ocean would seem to increase the likelihood that they will encounter far-ranging fishes. However, both commercial and recreational fishers consistently target species at particular sites based on their proximity to ports or past fishing successes, and therefore, fisher dispersal throughout the ocean is not evenly distributed. Similarly, the fact that half of all tagged fishes in this study were released within the boundaries of unfishable reserves decreases the probability that public anglers will recapture site-specific fishes. Fishing depth restrictions additionally preclude observations of fish traveling to deeper water. Our data indicate that a small portion of gopher and black rockfishes make significant movements (>10 km) away from their tagging sites (3\% and 8\%, respectively). This proportion of the total tagged fishes could potentially be larger if fishing effort were greater at distant fishing locations and more evenly distributed across a species' range. 
A similar perspective of our observed movement patterns as an artifact of the methodology used can be seen when considering the gear types used to capture and recapture gopher rockfish. The CCFRP trap study sites are in close proximity and of similar depth and habitat to those consistently utilized by local commercial live-fish trap fishers. The majority of fish recaptured by commercial trap fishers were gopher rockfish originally caught in traps and within $200 \mathrm{~m}$ of the tagging site. Therefore, the high percentage of gopher rockfish demonstrating small-scale movement is likely an accurate observation, but may not preclude further-ranging dispersal since fishing effort is not diffuse. In constrast, recreational fishers are not as site-specific in the species they target as are commercial fishers, and accordingly encountered more species and at greater distances from tagging sites in the current study.

Throughout the duration of the tag-and-recapture effort utilized in this study, I encountered a compliancy issue among members of the fishing community. This issue has also been reported in similar studies (Bacheler et al., 2008; Smith \& Scharf, 2009). A commercial fisher's deckhand anonymously returned 13 removed fish tags without any additional spatial, temporal, or fish length information along with the report that his captain did not support the tagging effort and would have otherwise discarded of all the tags. The majority (11 of 13 tags) pertained to gopher rockfish that had been caught during CCFRP trap surveys. Although the returned fish tags alone are valuable and contribute to the overall tag return rate, the additional information that we request from fishers is essential for understanding the movement behavior of interest in the current study as well as for a suite of other biological data. Without accurately reported data 
from public fishers and a sufficiently high tag return rate, a tag-and-recapture study is not a dependable source of fisheries information.

It is possible that more outreach to local fishing communities, as well as a higher reward value, would have increased the likelihood of compliancy for returned fish tags and information (Pollack et al., 2001; Green \& Matlock, 1983; Nichols et al., 1991). A similar tag-and-recapture study conducted on cabezon (Scorpaenichthys marmoratus) in San Luis Obispo County in 2004 achieved a higher tag return rate (16.1\%) than the current study (Mireles, 2005). In that project $\$ 35$ was paid for tag information and the fish itself for legal-sized cabezon, a value comparable to the market price. The current study paid only $\$ 20$ for tag information but permitted the fish to be kept by the fisher, thus potentially allowing for it to be sold at market. Various studies have estimated that a reward value of $\$ 50-100$ is necessary to ensure a tag reporting rate approaching $100 \%$, but rates are also influenced by geographic location and species (Pollack et al., 2001; Nichols et al., 1991; Green et al., 1983; Smith \& Scharf, 2009). Additionally, it is advised that the reward value be printed on the tag itself (Pollack et al., 2001). In the current study the reward for tags was advertised solely through flyers posted throughout the community. Furthermore, the implementation of marine reserves has proved to be contentious and some fishers may choose not to participate in the tag-return program as a political statement against them.

The limitations to understanding fish movement using tag-and-recapture techniques were further compounded when it became apparent that some degree of tag shedding had occurred during the current study. In the first three months of 2010, 30 loose tags were found washed ashore on Carmel Beach, California. All but one of the 
tags had been inserted into fish released at the Point Lobos MPA and reference sites, a distance of approximately three kilometers away. The one remaining tag had originally been inserted in a fish released in the Ano Nuevo MPA, approximately $50 \mathrm{~km}$ away. Additionally, two tags were found on beaches near the Ano Nuevo study area, one from a fish released at the area's reference site and the other from the Point Lobos MPA. It is possible that fish tags are sometimes rejected by the animal's body and eventually fall out, or are discarded by fishers. Or, a tagged fish could be eaten by a predator, after which the tag would pass through the predator's digestive tract and be excreted. It was hypothesized that the tags found on Carmel Beach may have been suspended in the 'Carmel ocean gyre' for several years and were deposited onshore due to altered current movements and storm patterns during the winter of 2010 (Starr et al., 2010).

I investigated the observed condition of a fish during the tagging process at the surface and upon its release by CCFRP field crew to determine if there was a relationship with travel distance. Survival rates are often assumed to be low for rockfish captured at depths greater than about 20-30 m because of injuries that can result from the rapid expansion of gases trapped in their closed swim bladders (barotrauma) (Starr et al., 2002). However, the effects of barotrauma appear to be highly species-specific, and the condition of different rockfish species at the surface may not be a good indicator of the relative potential for survival after submergence and recompression (Hannah \& Matteson, 2007). There was no evidence of a relationship between the observed condition of each fish and the distance traveled for black, gopher, or blue rockfishes, suggesting that our tagging methodology does not significantly affect movement behavior or fish survival rates. 


\subsection{Central Coast MPA Design and Spillover}

I examined the dimensions and distances between consecutive reserves

throughout the central coast study region, from Vandenberg SMR at the southern extent to Greyhound Rock SMCA in the north (fig. 5). The approximated mean reserve length is $6.7 \mathrm{~km}( \pm 1.2 \mathrm{SE})$ along the coast with a mean width of $3.6 \mathrm{~km}( \pm 0.8 \mathrm{SE})$.

Vandenberg SMR is the largest of the reserves and is approximately $21 \mathrm{~km}$ in length and $6 \mathrm{~km}$ in width, while Carmel Pinnacles is the smallest reserve at 1 square kilometer. The coastal reserves (excluding Elkhorn Slough and Morro Bay) are separated by $19 \mathrm{~km}$ on average $( \pm 5.3 \mathrm{SE})$. Based on the fact that $75 \%$ of all observed movements made by our 14 recaptured species were less than one kilometer, these reserve dimensions appear to be sufficiently large to afford consistent protection from fishing pressure and would continue to be effective if smaller in area. Due to the relatively large average distance between reserves in the network, transfer of adult fish between protected areas is not likely. In such a network configuration, with relatively large-sized reserves spaced over tens of kilometers, larval dispersal is a more probable driver of connectivity. The small percentage of individuals which are likely to make long-distance travels ensures that at least some export will occur.

The relatively infrequent boundary crossings out of reserves in the current study ( $5 \%$ of observed movements) demonstrates that export of adults is predictable, but to a limited degree. A single tagged fish was observed to move into a reserve from a fishable area, a behavior that could also be increasingly likely over time as protected areas offer 
advantages in the form of improved habitat quality and food availability (Tremain et al., 2004). The probability of spillover occurring is thought to be partly dependent on the shape of the reserve and on the habitat types near its boundaries. Emigration rates across a boundary are higher with a greater perimeter to area ratio, typically in a long thin shape with many sides as opposed to a round shape (Buechner, 1987). Broad sandy stretches can be a partial or complete barrier to the exchange of adult individuals between areas, possibly due to elevated predation exposure and habitat specificity. Based on bathymetric shaded relief profiles of the central coast study region, it appears that the rocky habitat represented within most MPAs extends well beyond reserve boundaries and along the coast, therefore increasing the likelihood that fish will travel throughout the reserve network.

The habitat specificity of the temperate reef species examined in the current study is demonstrated by the consistent bottom structure of their initial capture and recapture locations. When black, blue, and gopher rockfishes moved more than one kilometer from their tagging site, it always occurred from areas of moderate or high levels of bathymetric structure $(1 \mathrm{~m}$ to $\geq 3 \mathrm{~m})$ to similar habitat types according to bottom relief data recorded during CCFRP surveys. There was no evidence of a significant correlation between relief type and distance traveled for gopher rockfish, but most recaptured fish moved from a high-relief area. The single fish that was recaptured on two separate occasions at the same site one and two years after initial capture, was encountered over high relief habitat. Similarly, there appear to be distinct aggregations of recaptured fishes over high relief areas, suggesting that fish may travel to predetermined localities (McClanahan \& Mangi, 2000). 
SCUBA surveys, such as those conducted by the Partnership for Interdisciplinary Studies of Coastal Oceans (PISCO), have provided detailed information on the benthic structure of a portion of the central coast study region, and have proved useful in informing the MPA design process. PISCO has characterized the substrate and algal communities of the Point Lobos and Point Buchon SMRs to a depth of 20m. They reported high-relief contiguous bedrock and high densities of giant kelp (Macrocystis) in Point Lobos and low-relief bedrock with a greater abundance of bull kelp (Nereocystis) in Point Buchon. Such knowledge of habitats at potential reserve sites, as well the associated space usage patterns utilized by different temperate reef species, allow for optimal reserve size and placement decisions to be made.

I examined fish abundance (CPUE) at each site as an average over the sampling season to determine if there was a relationship between abundance and movement. Travel distances were not significantly correlated with fish abundance as other studies have both observed and demonstrated experimentally (Abesamis \& Russ, 2005; Amargos et al., 2010). Fish abundance, as measured by hook-and-line and trap catch rates, may not represent reality and certain species are found to be overly-represented by such techniques. In Matthews' (1986) study, gopher rockfish comprised 18\% of fishes caught by hook-and-line while they comprised only $1 \%$ of diver observations at the same sites. The study suggested that the species' territorial and aggressive behavior makes them more prone to fishing pressure, a scenario in which CPUE would not represent accurate fish abundance at a site. 


\section{Chapter 5. Conclusions and Future Research}

The current study provides further evidence that nearshore rockfish are highly site-specific over extended periods of time and likely throughout the duration of their lives. However, variations of behavioral types exist within and among species which counter broad generalizations. The three species most closely examined here represent a gradation of space-usage types within the Sebastes genus. Gopher rockfish have been found to be extremely territorial and aggressive with miniscule home ranges on rocky reefs (Larson, 1980a-c). Our recapture results portray this reality in the high percentage of tagged fish that were encountered within one kilometer of the tagging site. Additionally, the single gopher rockfish that was recaptured twice at its original tagging site one and two years after initial capture exemplifies the site fidelity of the species. Black rockfish, conversely, are territorial only during mating periods and are found both throughout the water column and associated with high- and low-relief habitat (Love et al., 2002). The species appears to represent a unique duality of behavioral types evidenced in their relatively high proportion of long-distance travels on the order of hundreds of kilometers as well as localized movement. Less is known about space usage by pelagic, schooling rockfish species, such as blue rockfishes, but our data support the previous findings of differential movement patterns with depth (Miller \& Geibel, 1973) wherein fish at depth travel greater distances. 
Our data do not indicate a marked difference in movement tendencies throughout the central coast region, suggesting that the current spatial scale of management appropriately addresses this biological aspect for the species surveyed. It appears that the nearshore groundfish encountered in the current study share much in common in their relative site fidelity but vary in the likelihood and impetus for their further-ranging movements. Black rockfish that traveled the greatest distances were those originally tagged in relatively shallow depths, while blue rockfish that moved away from their tagging site were originally captured deeper. The parameters inducing the farthestranging travels for gopher rockfish were not made clear in the analyses conducted. The complexity of species-habitat relationships and social dynamics is a probable driver for the variety of inter-specific movement patterns.

The tag-and-recapture techniques employed in this study allowed us to tag a large number of fish and detect their travel distances over a relatively long time period. We will likely continue to receive data from tag recaptures into the future, further clarifying our understanding of temperate reef fish movement. The limitations of tag-and-recapture data lie in the ambiguity of the movement behavior that occurs between capture events for a tagged fish. Although a large percentage of fishes in the current study were recaptured near their original tagging site, it is possible, but unlikely, that the fish traveled over great distances and returned to the tagging location. Additionally, some fish may be more susceptible to capture during certain seasons, and thus may be more likely to be caught in one location even though they utilized other areas (Lowe \& Bray, 2006). Due to the limited spatial resolution of these data, it is recommended that tag-andrecapture methods be employed in conjunction with remote sensing technologies, 
including acoustic or ultrasonic telemetry. An investigation combining a large-scale tagand-recapture component with tracking of acoustically tagged fishes would allow for both large-scale movements and more spatially-resolved daily habitat usage observations to be made. Diver observations would additionally contribute to the understanding of social dynamics and specific habitat preferences.

The conservation goals of a marine reserve or a network of multiple reserves should dictate the most important elements of its design. In utilizing MPAs for the purpose of fisheries preservation for shallow-water, nearshore reef species, reserves of very large size appear unnecessary based on the high percentage of small-scale movements for many species. Habitat quality may be of more importance than reserve size in terms of projected species and numbers to be protected. The likelihood of spillover and therefore a contribution into surrounding fishable areas could even be manipulated by placing a protected area over habitat type with limited capacity for supporting high fish density. The predictable density-dependent and territorial interactions observed in some species, such as gopher rockfish, increase the probability of adult export across reserve boundaries as individuals travel to satisfy their basic biological needs of food and shelter. Corridors of habitat connectivity will further augment the exchange of individuals between areas, both contributing to spillover and enhancing protection once individuals travel within reserve boundaries. The benefits of marine reserves are vast in their potential for ameliorating depressed fish populations, and a proper foundation of design built on species' ecological parameters will ensure optimal conservation success. 


\section{References}

Abesamis, R.A. and G.R. Russ. 2005. Density-dependent spillover from a marine reserve: long-term evidence. Ecological Applications 15(5): 1798-1812.

Allen, L.G.; D.J. Pondella II; M.H. Horn. 2006. The ecology of marine fishes: California and adjacent waters. University of California Press, Berkeley and Los Angeles, California: 660 pp.

Amargos, P.F.; G.G. Sanson; A. Jimenez del Castillo; A.Z. Fernandez; F.M. Blanco; W. Acosta de la Red. 2010. An experiment of fish spillover from a marine reserve in Cuba. Environ. Biol. Fish. 87: 363-372.

Attwood, C.G. and B.A. Bennett. 1995. Modeling the effect of marine reserves on the recreational shore-fishery of the south-western Cape, South Africa. South African Journal of Marine Science 16: 227-240.

Auster, H.M.; C.H. Turner, \& C. Limbaugh. 1996. Observations on fishes associated with kelp beds in Southern California. Calif. Dep. Fish Game, Fish Bull. 160, 144 p.

Bacheler, N.M.; J.E. Hightower; L.M. Paramore; J.A. Buckel; K.H. Pollack. 2008. An age-dependent tag return model for estimating mortality and selectivity of an estuarinedependent fish with high rates of catch and release. Trans. of the Amer. Fish. Soc. 137:1422-1432.

Beaumariage, J.A. 1969. Egg quality in fish: what makes a good egg? Fisheries Biology 7: 387-416.

Beverton J.R. \& T. Holt. 1957. Diurnal-nocturnal activity of some inshore fishes in the Gulf of California. Copeia 291-302.

Boersma, P.D. \& Parrish, J.K. 1999. Limiting abuse: marine protected areas, a limited solution. Ecological Economics 31:287-304.

Bohnsack, J.A. 1993. Marine Reserves: They Enhance Fisheries, Reduce Conflicts, and Protect Resources. Oceanus 36(3):63-71.

Buechner, M. 1987. Conservation in insular parks: Simulation models of factors affecting the movement of animals across park boundaries. Biological Conservation 41: $57-76$.

Buxton, A.R. \& M. Allen. 1989. Role of marine reserves in recruitment to reef fisheries: a metapopulation model. Biological Conservation 71: 197-204. 
Davies, G.E. 1989. Designated Harvest Refugia: The Next Stage of Marine Fishery Management in California. California Cooperative Oceanic Fish. Invest. Rep. 30:53-58.

Dewees, C.M. and D.W. Gotshall. 1974. An experimental artificial reef in Humboldt Bay, California. California Fish and Game 60(3): 109-127.

Ebeling, A.W. \& R.N. Bray. 1976. Day versus night activity of reef fishes in a kelp forest off Santa Barbara, California. Fishery Bulletin 74(4): 703-717.

Echeverria, T.W. 1987. Thirty-four species of California rockfishes: maturity and seasonality of reproduction. Fish. Bull. 85(2): 229-250.

Field, J.C.; A.E. Punt; R.D. Methot; C.J. Thomson. 2006. Does MPA mean 'Major Problem for Assessments'? Considering the consequences of place-based management systems. Fish and Fisheries 7: 284-302.

Francis, R.C.; J.E. Little; J. Bloeser. 2009. Matching spatial scales of ecology, economy, and management for groundfish of the U.S. west coast marine ecosystem: a state of the science review. Report to the Lenfest Ocean Program at The Pew Charitable Trust.

Gaines, S.D.; B. Gaylord; J.L. Largier. 2003. Avoiding current oversights in marine reserve design. Ecological Applications 13(1): S32-S46.

Gell, F.R. \& C.M. Roberts. 2003. Benefits beyond boundaries: the fishery effects of marine reserves. Trends in Ecology and Evolution 18(9):448-455.

Green, A.W. and G.C. Matlock. 1983. A method for directly estimating the tagreporting rate of anglers. Transactions of the Amer. Fish. Soc. 112:412-415.

Griffiths, M.H. \& C.G. Wilke. 2002. Long-term movement patterns of five temperatereef fishes (Pices:Sparidae): implications for marine reserves. Marine and Freshwater Research 53(2): 233-244.

Gunderson, J.K; P. Francour, F. Badalamenti, \& R. Chemello. 2008. Trophic cascades in benthic marine ecosystems: lessons for fisheries and protected-area management. Environmental Conservation 27(2): 179-200.

Halpern, B.S. 2003. The impact of marine reserves: Do reserves work and does reserve size matter? Ecological Applications 13(1): 117-137.

Halpern, B.S.; \& R.R. Warner. 2002. Marine reserves have rapid and lasting effects. Ecology Letters 5:361-366. 
Hannah, R.W. \& K.M. Matteson. 2007. Behavior of nine species of Pacific Rockfish after hook-and-line capture, recompression, and release. Trans. of the Amer. Fish. Soc. 136:24-33.

Harada, E. 1962. A contribution to the biology of the black rockfish S. inermis. Publ. Seto Mar. Biol. Lab. 5:307-361.

Hartmann, A.R. 1987. Movement of scorpionfishes (Scorpaenidae: Sebastes and Scorpaena) in the Southern California Bight. Deparment of Fish and Game, Fish Bulletin No. 73(2): 68-79.

Hoelzer, G.A. 1988. Juvenile movement patterns in a territorial scorpaenid fish before and during settlement. Marine Ecology Progress Series 45: 193-195.

Holland, K.N., J.D. Peterson, C.G Lowe, and B.M Wetherbee. 1993. Movements, distribution, and growth rates of the white goatfish Mulloides flavolineatus in a fisheries conservation zone. Bulletin of Marine Science 52(3): 982-992.

Jackson, J.B.C.; M.X. Kirby et al. 2001. Historical overfishing and the recent collapse of coastal ecosystems. Science 293: 629-638

Jagielo, T.H. 1990. Movement of tagged lingcod Ophiodon elongates at Neah Bay, Washington. Fishery Bulletin 88: 815-820.

Jiang, H.; C. Brownie; J.E. Hightower; K.H. Pollack. 2007. Estimating fishing mortality, natural mortality, and selectivity using recoveries from tagging young fish. North Amer. Jour. of Fish. Manag. 27:773-781.

Kaplan, D.M.; \& L.W. Botsford. 2005. Effects of variability in spacing of coastal marine reserves on fisheries yield and sustainability. Can. J. Aquat. Sci. 62: 905-912.

Kramer, J.A. \& F. Chapman. 1999. Effects of fishing on reef fish communities at Pedro Bank and Port Royal Cays, Jamaica. Marine Ecology Progress Series 43: 201-212.

Larson, R.J. 1980a. Territorial behavior of the black and yellow rockfish and gopher rockfish (Scorpaenidae, Sebastes). Marine Biology 58: 111-122.

Larson, R.J. 1980b. Influence of territoriality on adult density in two rockfishes of the genus Sebastes. Marine Biology 58: 123-132.

Larson, R.J. 1980c. Competition, habitat selection, and the bathymetric segregation of two rockfish (Sebastes) species. Ecological Monographs 50(2): 221-239.

Love, M.S. 1980. Isolation of olive rockfish, Sebastes Serranoides, populations off southern California. Fishery Bulletin 77(4): 975-983. 
Love, M.S. 1981. Evidence of movements of some deepwater rockfishes (Scorpaenidae: genus Sebastes) off southern California. California Fish and Game 67(4): 246-249.

Love, M.S., M. Yoklavich, and L. Thorsteinson. 2002. The rockfishes of the northeast Pacific. University of California Press, Berkeley: 405 pp.

Lowe, C.G., K.M. Anthony, E.T. Jarvis, L.F. Bellquist, and M.S. Love. 2009. Site fidelity and movement patterns of groundfish associated with offshore petroleum platforms in the Santa Barbara Channel. Marine and Coastal Fisheries: Dynamics, Management, and Ecosystem Science 1: 71-89.

Lowe, C.G.; B.M. Bray. 2006. Movement patterns, habitat utilization, home range size and site fidelity of whitesaddle goatfish, Parupeneus porphyreus, in a marine reserve. Environmental Biology of Fishes 59: 235-242.

Mathews, S.B. and M. LaRiviere. 1987. Movement of tagged lingcod, Ophiodon elongatus, in the Pacific Northwest. Fishery Bulletin 85(1): 153-159.

Mathews, S.B. and M.W. Barker. 1983. Movements of rockfish (Sebastes) tagged in northern Puget Sound, Washington. Fishery Bulletin 82(1): 916-922.

Matthews, K.R. 1986. Movement of two nearshore, territorial rockfishes previously reported as non-movers and implications to management. Calif. Fish and Game 72(2) 103-109.

Matthews, K.R. 1990. An experimental study of the habitat preferences and movement patterns of copper, quillback, and brown rockfishes (Sebastes spp.). Environmental Biology of Fishes 29: 161-178.

McClanahan, T.R. \& S. Mangi. 2000. Spillover of exploitable fishes from a marine park and its effect on the adjacent fishery. Ecological Applications 10(6): 1792-1805.

Miller, D.J. and J.J. Geibel. 1973. Summary of blue rockfish and lingcod life histories; A reef ecology study; and giant kelp, Macrocystis Pyrifera, experiments in Monterey Bay, California. California Department of Fish and Game, Fish Bulletin No. 158, 126p.

Mireles, C. 2005. A mark and recapture investigation on the commercial cabezon (Scorpaenichthys marmoratus) fishery off of Estero Reef: assessment of catch statistics and behavior on the south central coast of California. Senior Project. California Polytechnic State University, San Luis Obispo. 37p.

Mitamura, H; N. Arai; W. Sakamoto; Y. Mitsunaga; H. Tanaka; Y. Mukai; M. Sasaki; Y. Yoneda. 2005. Role of olfaction and vision in homing behavior of black rockfish Sebastes inermis. Jour. Of Exper. Mar. Biol. \& Ecol. 322:123-134. 
Nichols, J.D.; R.J. Blohm; R.E. Reynolds; R.E. Trost; J.E. Hines; J.P. Bladen. 1991. Band reporting rates for mallards with reward bands of different dollar values. J. Wild. Manage. 55(1): 119-126.

Parsons, D.M.; M.A. Morrison; M.J. Slater. 2010. Responses to marine reserves: Decreased dispersion of the sparid Pagrus auratus (snapper). Biological Conservation 143: 2039-2048.

Pearcy, W. G. 1992. Movements of acoustically-tagged yellowtail rockfish Sebastes flavidus on Heceta Bank, Oregon. Fishery Bulletin 100:726-735.

Pollock, K.H.; J.M. Hoening; W.S. Hearn; B. Calingaert. 2001. Tag reporting rate estimation: An Evaluation of the high-reward tagging method. North Amer. Journal of Fish. Manag. 21:521-532.

Rowley, R.J. 1994. Marine Reserves in Fisheries Management. Aquatic Conservation 4:233- 254.

Russ, G.R. \& A.C. Alcala. 1996. Do marine reserves export adult fish biomass? Evidence from Apo Island, central Philippines. Mar. Ecol. Prog. Ser. 132: 1-9.

Shinomiya, A. \& A. Ezaki. 1991. Mating habits of the rockfish Sebastes inermis. Environ. Biol. Fishes 30:15-22.

Smith, W.E. \& F.S. Scharf. 2009. Fishing mortality in North Carolina's southern flounder fishery: direct estimates of instantaneous fishing mortality from a tag return experiment. Marine and Coastal Fisheries: Dynamics, Management, and Ecosystem Science 1: 283-299.

Stanley, R.D, B.M. Leaman, L. Haldorson, and V.M. O’Connell. 1994. Movements of tagged adult yellowtail rockfish, Sebastes flavidus, off the west coast of North America. Fishery Bulletin 92(3): 655-663.

Starr, R.M; D.W. Wendt, K.T. Schmidt, R. Romero, J. Duryea, E. Loury, N. Yochum, R. Nakamura. 2010. Baseline surveys of nearshore fishes in and near central California marine protected areas 2007-2009. Final Project Report Submitted to the Ocean Protection Council. 22 April 2010.

Starr, R.M., J.N. Heine, J.M. Felton, and G.M. Caillet. 2002. Movements of bocaccio (Sebastes paucispinis) and greenspotted (S. chlorostictus) rockfishes in a Monterey submarine canyon: implications for the design of marine reserves. Fishery Bulletin 100:324-337. 
Starr, R.M. \& K. Green. 2007. Species composition, relative abundance, and movements of important nearshore fish species along the north central California coast. Final report to the Pacific States Marine Fisheries Commission.

Starr.R.M., V. O'Connell, and S. Ralston. 2004. Movements of lingcod (Ophiodon elongatus) in southeast Alaska: potential for increased conservation and yield from marine reserves. Canadian Journal of Fisheries and Aquatic Sciences 61: 1083-1094.

Stein, J. 1997. Home range, movement, and space use of olive rockfish (Sebastes serranoides) in the proposed Edward F. Ricketts Marine Park, Monterey, California. Masters Thesis. California Polytechnic State University, San Luis Obispo. 46p.

Topping, D.T., C.G. Lowe, and J.E. Caselle. 2006. Site fidelity and seasonal movement patterns of adult California Sheephead Semicossyphus pulcher (Labridae): an acoustic monitoring study. Marine Ecology Progress Series 326: 257-267.

Tremain, D.M.; C.W. Harnden; D.H. Adams. 2004. Multidirectional movements of sportfish species between an estuarine no-take zone and surrounding waters of the Indian River Lagoon, Florida. Fish. Bull. 102: 533-544.

Turner, C. H., E.E. Ebert, and R.R. Given. 1969. Man-made reef ecology. California Department of Fish and Game, Fish Bulletin No. 146, 221p.

Walters, C.J.; R. Hilborn; R. Parrish. 2007. An equilibrium model for predicting the efficacy of marine protected areas in coastal environments. Can. J. Fish. Aquat. Sci. 64: 1009-1018.

Willis, T.J.; R.B. Millar; R.C. Babcock; N. Tolimieri. 2003. Burdens of evidence and the benefits of marine reserves: putting Descartes before des horse. Environmental Conservation 30(2): 97-103.

World Resources Institute. 1996. World Resources: A Guide to the Global Environment: The Urban Environment 1996-97. Oxford University Press, Oxford, 365 pp.

Zeller, D.; S.L. Stoute; G.R. Russ. 2003. Movements of reef fishes across marine reserve boundaries: effects of manipulating a density gradient. Mar. Ecol. Prog. Series. 254: 269-280. 